\title{
An Atlas of Piezoelectric Energy Harvesters in Oceanic Applications
}

\author{
Seyyed Masoud Kargar (1) and Guangbo Hao * \\ School of Engineering and Architecture, University College Cork, T12K8AF Cork, Ireland; \\ 120222847@umail.ucc.ie \\ * Correspondence: g.hao@ucc.ie
}

Citation: Kargar, S.M.; Hao, G. An Atlas of Piezoelectric Energy Harvesters in Oceanic Applications. Sensors 2022, 22, 1949. https:// doi.org/10.3390/s22051949

Academic Editor: Chang Kyu Jeong

Received: 18 January 2022

Accepted: 27 February 2022

Published: 2 March 2022

Publisher's Note: MDPI stays neutral with regard to jurisdictional claims in published maps and institutional affiliations.

Copyright: (C) 2022 by the authors. Licensee MDPI, Basel, Switzerland. This article is an open access article distributed under the terms and conditions of the Creative Commons Attribution (CC BY) license (https:// creativecommons.org/licenses/by/ $4.0 /)$.

\begin{abstract}
Nowadays, a large number of sensors are employed in the oceans to collect data for further analysis, which leads to a large number of demands for battery elimination in electronics due to the size reduction, environmental issues, and its laborious, pricy, and time-consuming recharge or replacement. Numerous methods for direct energy harvesting have been developed to power these low-power consumption sensors. Among all the developed harvesters, piezoelectric energy harvesters offer the most promise for eliminating batteries from future devices. These devices do not require maintenance, and they have compact and simple structures that can be attached to low-power devices to directly generate high-density power. In the present study, an atlas of 85 designs of piezoelectric energy harvesters in oceanic applications that have recently been reported in the stateof-the-art is provided. The atlas categorizes these designs based on their configurations, including cantilever beam, diaphragm, stacked, and cymbal configurations, and provides insightful information on their material, coupling modes, location, and power range. A set of unified schematics are drawn to show their working principles in this atlas. Moreover, all the concepts in the atlas are critically discussed in the body of this review. Different aspects of oceanic piezoelectric energy harvesters are also discussed in detail to address the challenges in the field and identify the research gaps.
\end{abstract}

Keywords: piezoelectric; energy harvesting; ocean; energy conversion; atlas

\section{Introduction}

With the development of oceanic industries, the risks of polluting the oceans are gradually increasing. To solve this type of problem, ocean monitoring devices, such as different kinds of sensors, are developed. Sensors can collect data from distant places and send it to the stations nearby [1].

Employing technologies, such as Micro-Electro-Mechanical-Systems (MEMS), has introduced many low-energy consumption sensors to ocean pollution and water quality analyses. Miniaturization, diminishing power consumption, and portability are the most common trends in the newly emerged sensors and electronic devices [2]. These sensors simply collect data from the ocean and send it to stations for further analysis. Conventionally, these devices have been powered by chemical batteries. However, most often, the life of the batteries is shorter than the life of the sensors. Therefore, the batteries require replacement or recharge, and both of these actions are very pricy, time-consuming, and laborious. Moreover, as batteries are bulky and heavy, they hinder the development of miniature, as well as light, electronic devices. On the other hand, the possibility of polluting the environment by the leaking of the dangerous chemicals inside batteries threatens oceans and the animals living in them. Therefore, it is of high importance to eliminate batteries from oceanic devices and make them self-powered [3,4].

Considering that there are many types of renewable energy sources in the oceans in the form of mechanical energy (such as waves, tides, and currents), a high amount of research is devoted to developing technologies for energy conversion. Most recently, as 
oceans contain a huge amount of energy and are completely predictable and reliable, the generation of electricity based on oceans is becoming very popular. Electricity generation from oceanic energies can be either on large-scales [5], such as wave activated bodies [6], point absorbers [7,8], oscillating water columns [9], and overtopping [10] concepts, for cities and industries, or on small-scales using piezoelectric [11], electrostatics [12], electromagnetics [13], and triboelectric [14] devices for powering low power devices, such as the internet of underwater things, sensors, and other monitoring devices in oceans [15].

Recent progress in oceanic energy harvesting shows that batteries and cables will be eliminated in future electronics and will be replaced by clean power that does not introduce any environmental issues.

Among different small-scale energy harvesters, piezoelectric materials show a considerable energy generation density that is about three times higher than the others [16]. Moreover, these materials can be simply attached to the systems, and as they contain no moving parts, they are free from frequent upkeep. Moreover, they have the merits of direct conversion of energy to electricity, being compact, structurally simple, clean, lightweight, stable, and very sensitive to any small strains. Although the generated electricity by piezoelectric energy harvesters is rather small, it is enough for low energy consumption electronics, such as oceanic sensors [3].

Numerous piezoelectric energy harvesters with suitable properties for different applications have been developed. These include applications in transportation [17], smart systems [18], microfluidics [19], tissue engineering [20], implantable/wearable electronics [21], biomedical engineering [22], wind energy [23], and ocean energy [24]. Piezoelectric materials started to be used in the ocean as a power extractor mechanism in the 1970s [11]. However, large-scale ( $\mathrm{kW}$ range) power generation from ocean energy making use of piezoelectric materials is still under research [25].

Considerable excellent state-of-the-art surveys have been provided in the field of piezoelectric energy harvesters and oceanic piezoelectric energy harvesters. Jbaily et al. considered different aspects of piezoelectric devices and their working mechanism in oceanic applications [11]. Viet et al. compared the other energy harvesters in oceanic applications with piezoelectric energy harvesters and categorized the former literature and prototypes based on their piezoelectric coupling modes [26]. Kim has reviewed electroactive polymers for ocean kinetic energy harvesting [27]. Kiran et al. presented a review of different aspects of piezoelectricity and provided a historical state-of-the-art in the piezoelectric energy harvesters in the ocean [28]. There are, however, other reviews in the field [2,3,29] but none of them compiled a comprehensive atlas of piezoelectric energy harvesters' design. The present study is entirely dedicated to piezoelectric energy harvesters in oceanic applications because they are receiving massive attention most recently and growing quickly. In this regard, the next section of this review is dedicated to oceanic piezoelectric energy harvesters, which reviews piezoelectricity, piezoelectric materials in ocean energy harvesting applications, piezoelectric coupling modes, and classification of piezoelectric energy harvesters based on device structure, power harvesting system, ocean energy sources, and the location of the oceanic facilities. Next, the atlas of 85 piezoelectric energy harvesters is presented through four classifications; (1) Cantilever beam-based piezoelectric energy harvesters; (2) Diaphragm-based piezoelectric energy harvesters; (3) Stacked-based piezoelectric energy harvesters; (4) Cymbal-based piezoelectric energy harvesters. In the end, the future perspectives and challenges are discussed thoroughly.

\section{Oceanic Piezoelectric Energy Harvesters}

\subsection{Piezoelectricity}

In 1880, the term piezoelectricity was introduced by brothers Pierre and Jacques Curie [30], which has been intensively studied in recent years for different sensory and actuation applications in different fields. Later, in 1881, the brothers Curie validated their work on the inverse piezoelectric effect with experiments [3]. Stressing a piezoelectric material would result in a change in its atomic configuration, which forms dipole moments. 
This phenomenon is called the direct piezoelectric effect, in which the piezoelectric material generates electricity as a reaction to the applied force. Therefore, if a periodic force (tension or compression) is applied to the material, an alternative current (AC) voltage will be the output. On the other hand, if the piezoelectric material is electrically polarized, the converse piezoelectric effect appears in which the piezoelectric material extends/contracts as a result of the applied electrical voltage. It should be noted that in the inverse piezoelectric effect, lengthening or shortening of the piezoelectric material depends on the polarity and the applied poling voltage and can be reversed if the voltage direction is reversed [11]. Both the direct and converse effects of piezoelectricity are shown in Figure 1.
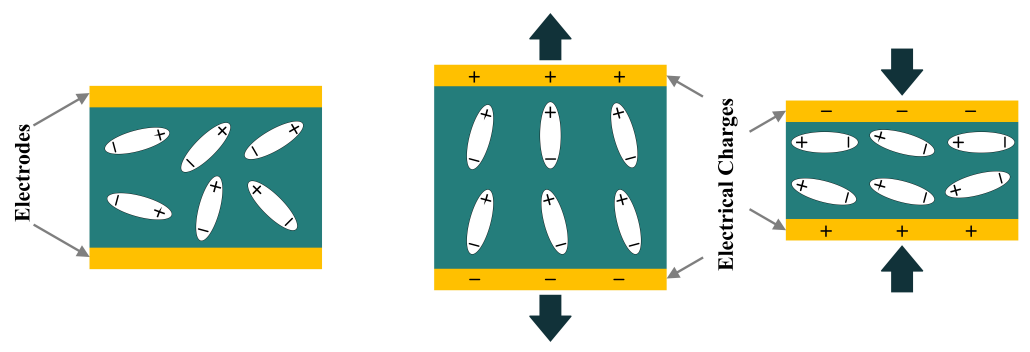

a) Direct Piezoelectric Effect
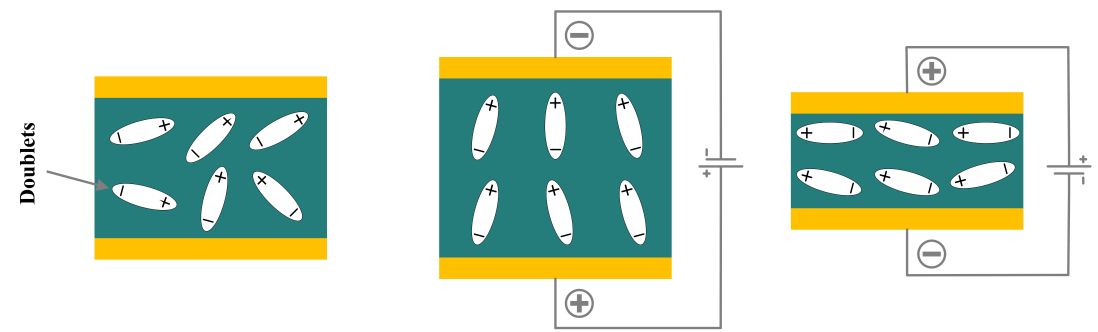

b) Converse Piezoelectric Effect

Figure 1. Piezoelectric Effect; (a) Direct Piezoelectric Effect; (b) Converse Piezoelectric Effect.

There are many diverse applications for both direct and inverse piezoelectric effects, where the direct effect is utilized in the case of sensors and energy harvesters, and the inverse effect is used in actuators. These effects are governed by piezoelectric constitutive equations as [31]:

$$
\begin{aligned}
& D=d T+\varepsilon E \\
& X=s T+d E
\end{aligned}
$$

where $D, d, T, \varepsilon, E, X$, and $s$, represent electrical displacement, piezoelectric coefficient, stress, the permittivity of the material, electric field, strain, and mechanical compliance, respectively.

\subsection{Piezoelectric Materials}

Active materials that can generate electricity as a reaction to small mechanical stress are called piezoelectric materials. The type of material for energy harvesting applications is of high importance to the performance and functionality of the harvester. Researchers have investigated numerous types of materials, such as organic, inorganic, composite, and bio-inspired materials, for piezoelectric energy harvesters [31]. Among them, PZT and PVDF are the most widely used materials for energy harvesting in oceanic applications. PZT, which is also known as Lead Zirconate Titanate, is a polled ferroelectric ceramic with the highest frequency of applications in piezoelectric energy harvesters. Even though the PZT is one of the major materials in energy harvesting, its drawbacks, such as its drastic brittle nature and fatigue growth possibility in high-frequency loadings, limited its 
widespread usage in energy harvesting. On the other hand, to overcome the demerits of PZT, PVDF, also known as polyvinylidene fluoride, is developed to improve the efficiency of piezoelectric energy harvesters [32]. Although PZT can produce more electricity when subjected to the same stress as PVDF, unlike PVDF, it cannot bear high stress. PVDF shows a higher tensile strength value, which is about 2.6 times higher than PZT's strength value [11]. The low stiffness, large tensile strength, and high flexibility of PVDF make it a unique choice for many applications, specifically in ocean energy harvesters. Apart from PZT and PVDF, macro-fiber composites (MFC) are also used in some of the literature in ocean applications, which show great performance in energy harvesting from the ocean.

\subsection{Coupling Modes}

Piezoelectric materials present a kind of flexibility in their configurations, which makes them unique in energy harvesting applications. Based on the desired configuration in a particular application, piezoelectric materials' configurations can be altered by changing their electrode pattern, poling direction, and strain direction. Moreover, to tune the resonant frequency between the material and the energy source, volume and layers can be changed, and a pre-load force can be added [27].

The piezoelectric coefficient $\left(d_{i j}\right)$ is the ratio of the strain to the electric field, where $i$ denotes the direction of the polarity and $j$ represents the mechanical stress direction. Figure 2 shows piezoelectric material axes for polarization, as well as stress/strain. According to [28], $d_{14}, d_{15}, d_{33}$, and $d_{31}$, or simply 1-4, 1-5, 3-3, and 3-1, respectively, are the piezoelectric energy harvesters' configurations in oceanic applications. However, due to the complex configurations of 1-4 and 1-5 modes, they are less used in oceanic applications compared to 3-3 and 3-1 modes. Figure 3 shows the most utilized configurations, 3-3 and 3-1, in ocean applications. In the 3-3 mode, both the polarity and the mechanical stress are in the same direction, parallel to each other. However, in the case of 3-1, the direction of the mechanical stress is perpendicular to that of polarity [33]. It should also be noted that choosing the right configuration for designing a high-performance piezoelectric energy harvester plays a crucial role and thus should be carefully considered based on the design requirements.
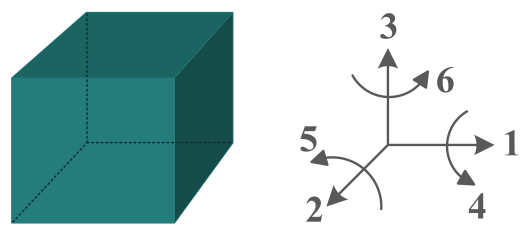

Figure 2. Polarization axes of piezoelectric materials.
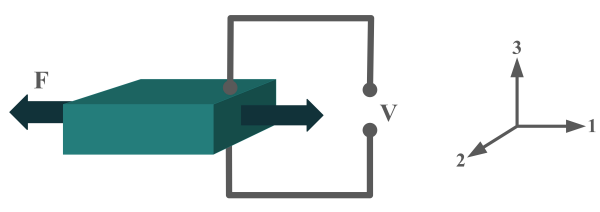

a) 3-1 Coupling
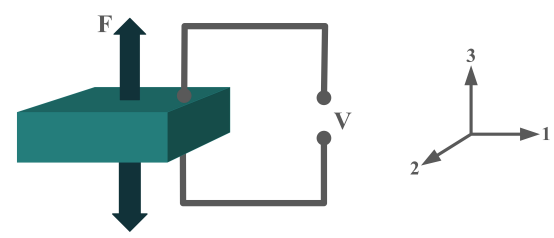

b) 3-3 Coupling

Figure 3. Piezoelectric Coupling Modes; (a) 3-1 Coupling Mode; (b) 3-3 Coupling Mode. 


\subsection{Classification Based on Device Structure}

The most common structure for a piezoelectric energy harvesting device is the cantilever beam configuration. This type of harvester employs one or two piezoelectric layers and is called unimorph and bimorph, respectively. Figure 4 shows cantilever beam structures with one and two layers of piezoelectric materials. As can be seen in Figure 4, piezoelectric layers are mostly bonded to a metallic non-piezoelectric material that is fixed at one end and acts as a flexural structure. As it is clear, taking advantage of two layers of piezoelectric materials, bimorph-type cantilever beams are capable of generating more output power compared to unimorph configurations. Therefore, bimorph configurations are of the high frequency of applications in piezoelectric energy harvesters [34,35].

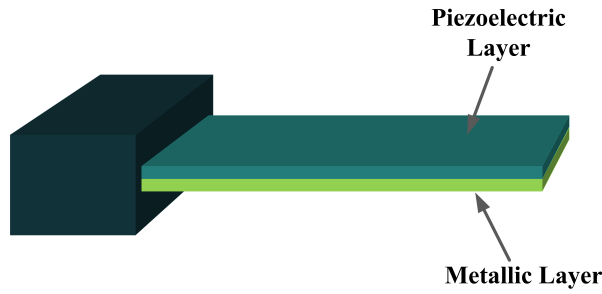

a) Unimorph Cantilever Beam

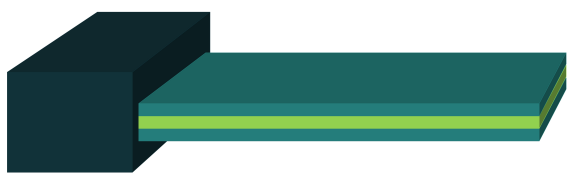

b) Bimorph Cantilever Beam

Figure 4. Cantilever Beam Configuration; (a) Unimorph; (b) Bimorph.

Cantilever beam configuration utilizes the 3-1 coupling mode most often. However, there are designs in the literature that have used 3-3 coupling modes for cantilever structures, making use of interdigitated electrode designs. Moreover, it is usual to add a proof mass at the free end of the cantilever beam to tune the resonant frequency of the harvester with the environment [31].

The other configuration, which consists of a piezoelectric layer with a mostly disk shape, is the diaphragm structure. The piezoelectric layer is bonded to a metal shim. In some configurations, to improve functionality under low frequencies and to add a preloading unit to the energy harvester, a proof mass is attached to the diaphragm's core (Figure 5) [36].
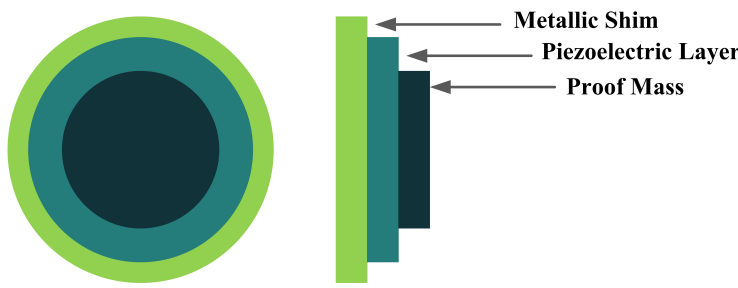

Figure 5. Diaphragm Configuration.

Adding two metallic endcaps in the shape of a cymbal on both sides of a piezoelectric disk would result in a new configuration called the cymbal structure (Figure 6). This configuration is indeed used to improve piezoelectric endurance when it is subjected to higher loads and impact forces. Moreover, the cymbal shape of the endcaps acts as a mechanical amplification unit due to the presence of the cavity in the center [36]. 
In addition to the other configurations, stacked piezoelectric structures can bear higher pressures. This configuration is made up of multiple layers of piezoelectric material stacked on top of each other. The poling direction of this type should be aligned with the applied force direction, as shown in Figure 7 [35].

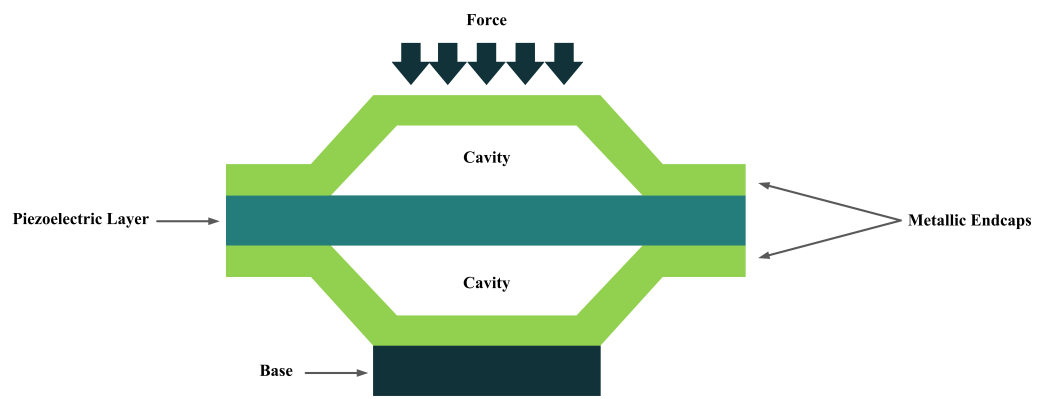

Figure 6. Cymbal Configuration.

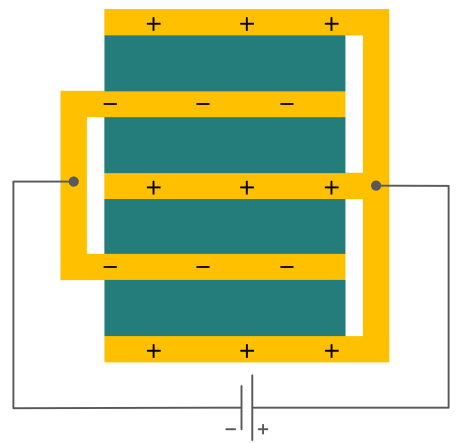

Figure 7. Stacked Configuration.

All the aforementioned configurations have their own merits and drawbacks. Each of them may be suitable for numerous applications and unsuitable for many others. Therefore, before employing one of them in an application, their limitations should be carefully studied and considered. In addition to the cantilever beam configuration's advantages, such as simple structure, low price, suitability for low-frequency applications, and higher mechanical quality factor, they are not able to withstand high impact forces. On the other hand, the cymbal configuration can bear impact forces and provide high energy output. However, the loss of mechanical input energy and being limited to applications requiring high vibration sources are its drawbacks. The circular diaphragm configuration is capable of working in pressure mode operations, but in a vibration mode application, it requires higher resonance frequencies. The stacked configuration is also suitable for working in pressure mode. It can also bear higher mechanical forces and provide higher outputs in the $\mathrm{d}_{33}$ coupling mode. Nevertheless, its high stiffness is among the challenges that should be addressed in the search for a proper application for it [36].

\subsection{Power Harvesting System}

The generated electricity by the piezoelectric energy harvesters needs to be further processed before any collection or storage in a power storage system. However, it should be taken into consideration that power storage systems, such as batteries, require direct current (DC) rather than alternative current (AC). If the piezoelectric harvester acts as a resonator, then the resultant voltage would be a sinusoidal signal, which should be rectified for any further applications. To carry out this operation, an intermediate step needs to be implemented to convert AC signals to DC. To do so, either the Standard Technique or the Synchronized Switch Harvesting on Inductor Technique can be employed [37,38]. By eliminating the ripple voltage, these techniques would smooth out the DC signal, and after regulation by the control system, the signal is ready to be stored in a power storage 
system. Figure 8 provides an illustration of the power harvesting operation by piezoelectric materials to further simplify the understanding of the process.

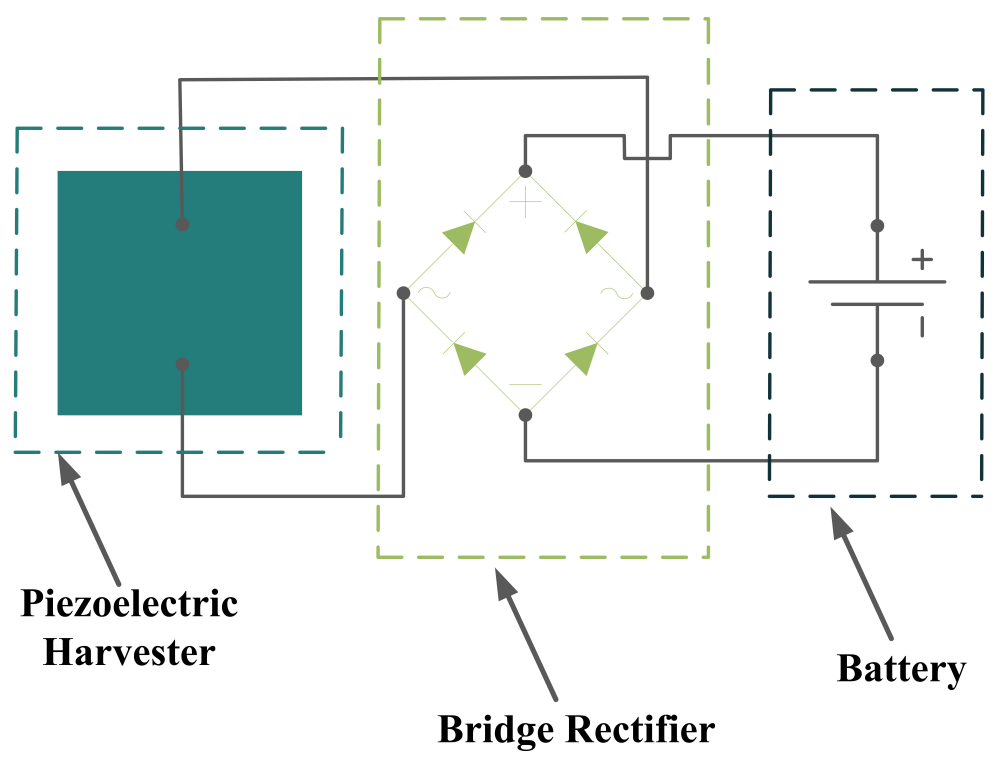

a) Energy Harvesting System

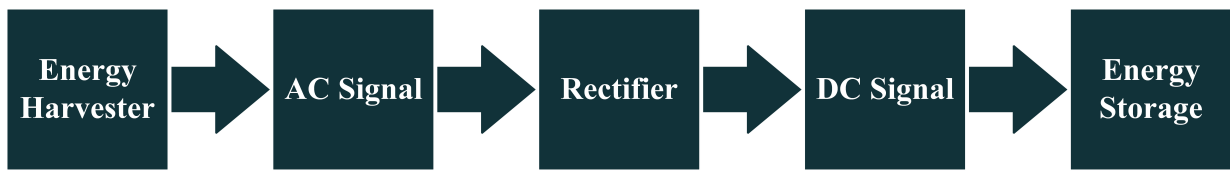

b) Energy Harvesting to Storage Steps

Figure 8. Power Harvesting Operation; (a) Energy Harvesting System; (b) Energy Harvesting to Storage Steps.

In addition to the circuit shown in Figure 8, there should be an impedance-matching system in between to guarantee the high performance of the piezoelectric energy harvesters. Matching the electrical parameters with the source, cable, or receiver is of high importance for any electrical transmission line that is involved in the transfer of an electrical signal or power. Therefore, the impedance matching of the electrical parameters should be carefully considered in the design stage of the piezoelectric energy harvesters [39]. According to [39], matching of both acoustic and electrical components in a design should be considered for impedance matching. However, in the case of piezoelectric energy harvesters, the impedance matching of electrical components is more important. Piezoelectric energy harvesters are narrow-banded intrinsically, but a broadband operation is required for energy harvesting, in which acoustic impedance matching is employed to improve the narrow-band operation. However, it increases the electrical impedance and leads to an impedance mismatch between the harvester and the interface device. This mismatch diminishes the electric energy and requires an electrical impedance matching unit to be minimized. To do so, a shunt circuit [40], which is the simplest one for this purpose, can be employed to maximize the output electrical energy (Figure 9). One can refer to [39-42] for more information regarding the impedance matching of piezoelectric energy harvesters. 


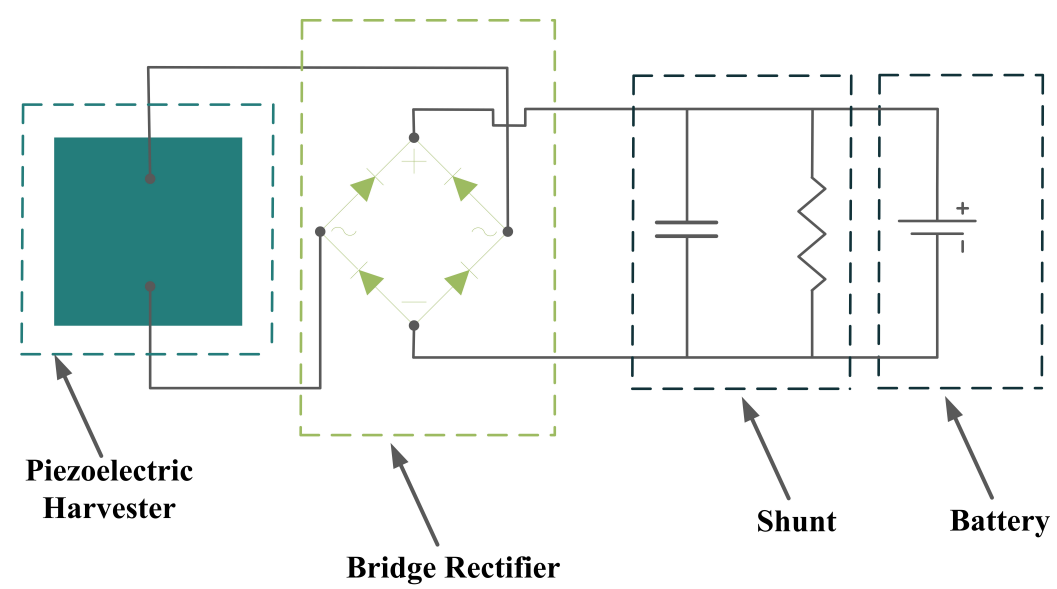

Figure 9. Energy Harvesting System with an Impedance Matching Unit (Shunt).

\subsection{Ocean Energy Sources for Piezoelectric Energy Harvesters}

Marine renewable energies are the source of many different energy converters $[5,43]$. In the case of piezoelectric energy harvesters, water current, wave motion, and wave impact forces have been employed to extract energy from the ocean and convert it to usable electrical energy to power sensors and some other measurement devices [11]. These sources are very promising and available at all times during the day. Moreover, these energy sources in marine environments have a high density compared to the other sources of renewable energies, such as wind or solar energies [44]. In the following, a short introduction will be given to each of the marine energy sources that piezoelectric energy harvesters are designed for.

\subsubsection{Water Currents}

To employ piezoelectric energy harvesters to extract power from ocean water currents, the vibration in the water can be converted to electricity. To do so, the piezoelectric energy harvester should be placed in the current stream and be coupled with flow-induced vibration. Vortex-Induced Vibrations (VIV) and Self-Excited Vibrations (SEV) are the two significant flow-induced vibrations that are exploited by piezoelectric energy harvesters $[45,46]$.

To create VIV, a bluff body is located in a water stream, and depending on the characteristics of the bluff body, vortices of a particular size and frequency appear. If, then, the piezoelectric energy harvester is placed behind the body, the generated vortices make it oscillate. This oscillation will generate electricity based on the piezoelectric principle [45].

Through the use of self-excitation of flexible bodies, here most often PVDF materials, SEV-based energy harvesting can be achieved. The bodies are placed in the flow stream and, by a minute increase in flow speed, the body attains self-excitation, which can be further used for electrical energy generation [46].

\subsubsection{Wave Motion}

Waves in the oceans are generated by the association of forces, such as wind, atmospheric pressure gradients, earthquakes, gravitational attraction, and storms. Moreover, these waves need to be restored using mechanisms such as surface tension, gravity, and Coriolis force. Based on their periods, waves can be classified into seven groups: (1) Capillary waves; (2) Ultra-gravity waves; (3) Gravity waves; (4) Infra-gravity waves; (5) Long-period waves; (6) Ordinary tidal waves; and (7) Trans-tidal waves [47].

There are two main factors in determining how much energy a wave holds (Figure 10): wave height and the wave's period [48], meaning the time taken for a wave crest to travel the distance between two wave crests. Waves with a greater height and shorter periods contain more energy. However, unlike water currents where the energy is distributed all 
along, the waves' energy density diminishes by the depth and is concentrated near the surface of the ocean. Therefore, the facilities' tip that captures the wave's energy should be close to the surface of the ocean [49]. According to [11,50], piezoelectric energy harvesters from wave motion mainly consist of heaving and pitching bodies, the PVDF layer on the surface of the ocean, and fixed bodies on the ocean bottom.

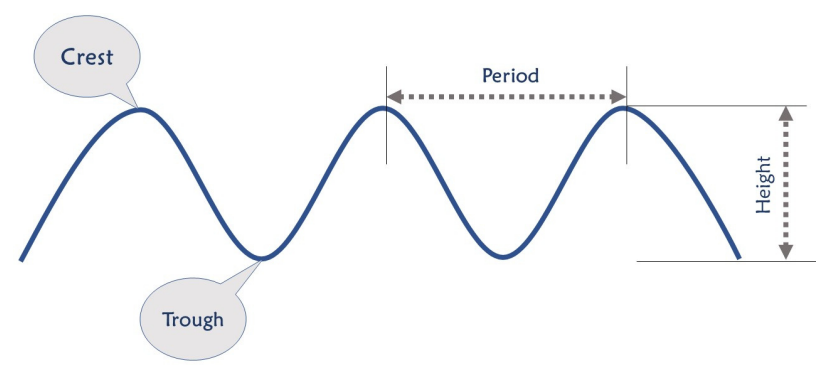

Figure 10. Characteristics of an Oceanic Wave.

\subsubsection{Wave Impact}

Another feature of the ocean is the impact of the waves on the ocean structure [50]. Mostly, wave impacts are considered destructive forces. However, these waves' forces on the structures can be advantageous rather than being devastating. In the case that the piezoelectric energy harvesters are placed on the surfaces that are subjected to waves impact, they can convert the applied pressure to electricity [11].

\subsection{Location}

Based on where the marine facilities are working, they can be categorized into three groups; onshore; nearshore; and offshore. Onshore represents regions with 10-15 m water depth, where this value is $15-25 \mathrm{~m}$ for nearshore, and is higher than $50 \mathrm{~m}$ for offshore. Figure 11 shows the different regions in the ocean [51].

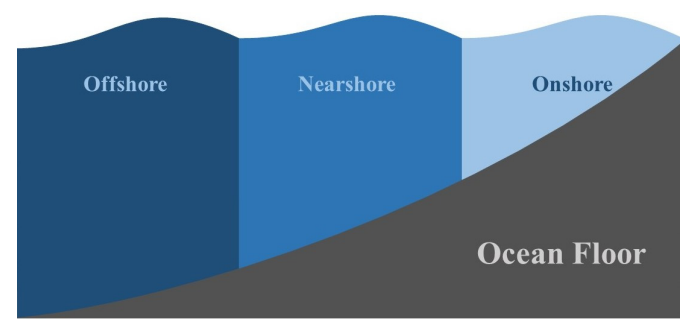

Figure 11. Ocean Regions.

\section{The ATLAS}

The following comprehensive atlas of 84 designs contains information on the utilized piezoelectric materials, piezoelectric coupling modes, location, power range, energy source, and a schematic of the piezoelectric energy harvesters design in oceanic engineering. It should be noted that all the information is collected exactly from the related references without any judgments and changes. The atlas includes just the information that the research articles provided, and in the cases where there is no information in any of the atlas's sections, the related unit is free of information. Moreover, the atlas only includes designs for which they have at least provided a simulation or fabricated and tested a prototype. The schematics are sketched in a way to help future designers simply understand the working principles of the state-of-the-art. Table 1 shows the meaning of different colors in the schematics to fully understand the concepts. Tables $2-5$ show the atlases of cantilever beam-based, diaphragm-based, stacked-based, and cymbal-based designs, respectively. 
Table 1. Meaning of each color in the atlas.

\begin{tabular}{cc}
\hline Color & Meaning \\
\hline & Buoy \\
& Magnet \\
& Piezoelectric Layer \\
The Other Colors & Water \\
\hline
\end{tabular}

Table 2. Atlas of cantilever beam-based piezoelectric energy harvesters.

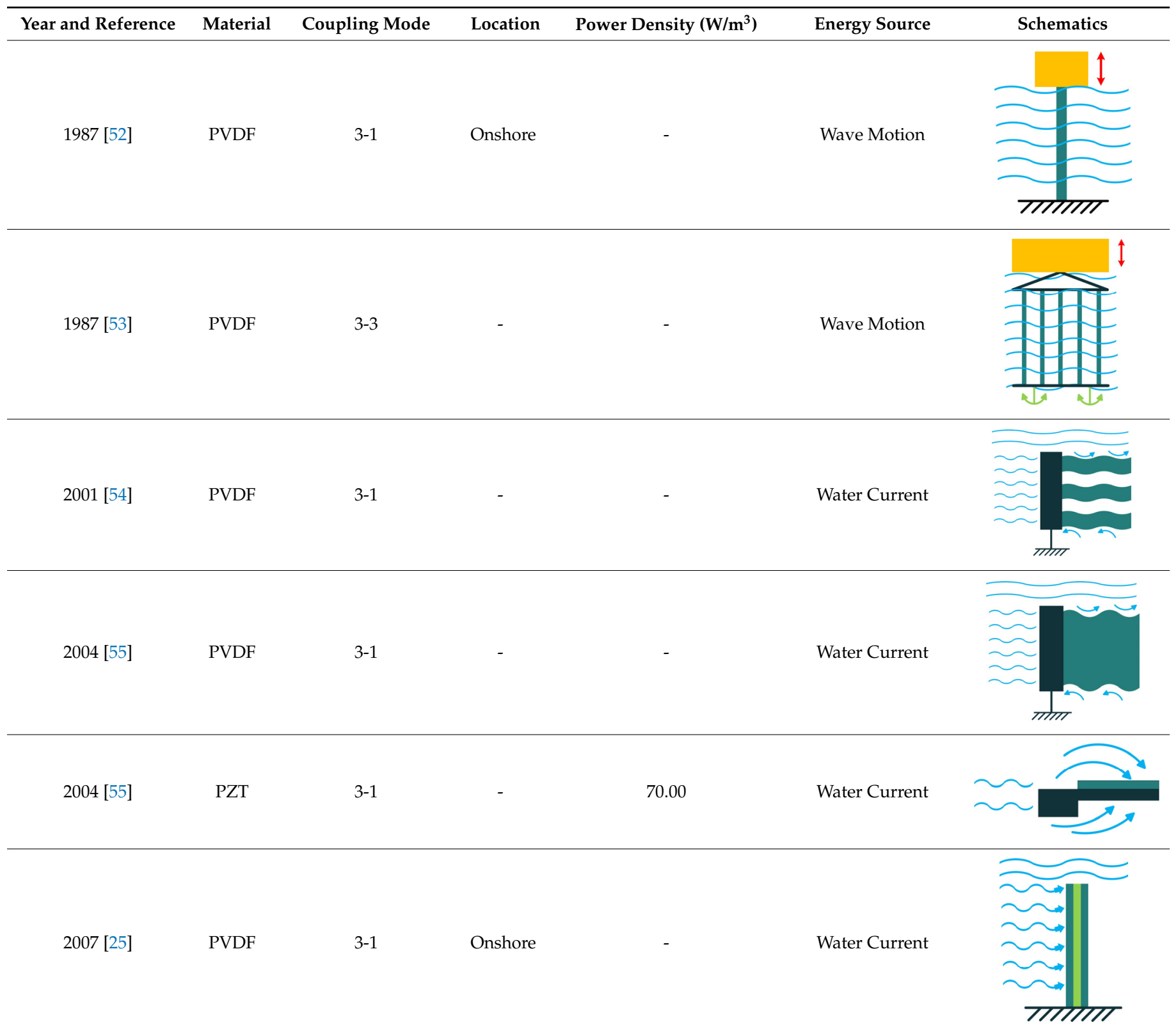


Table 2. Cont.

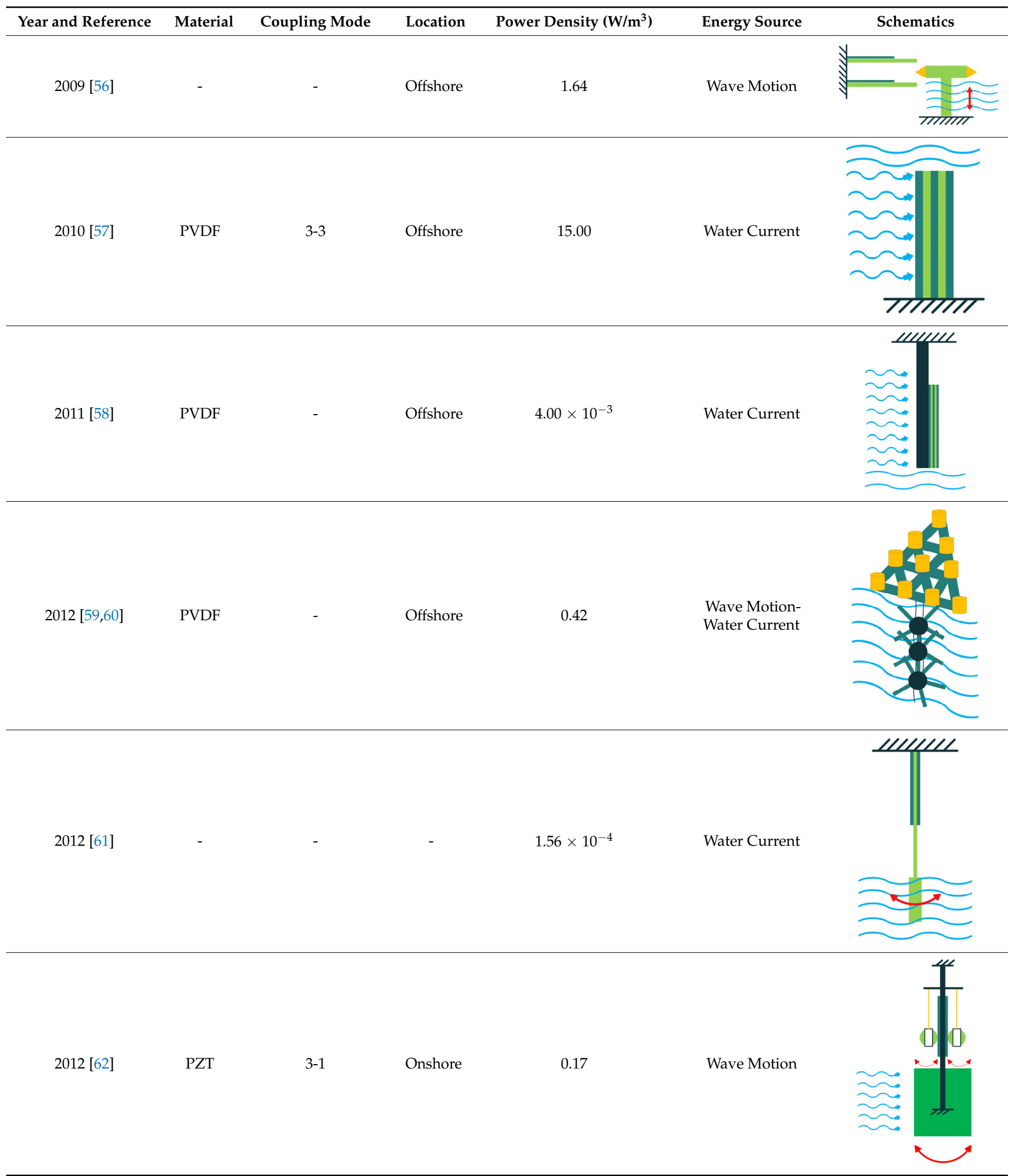


Table 2. Cont.

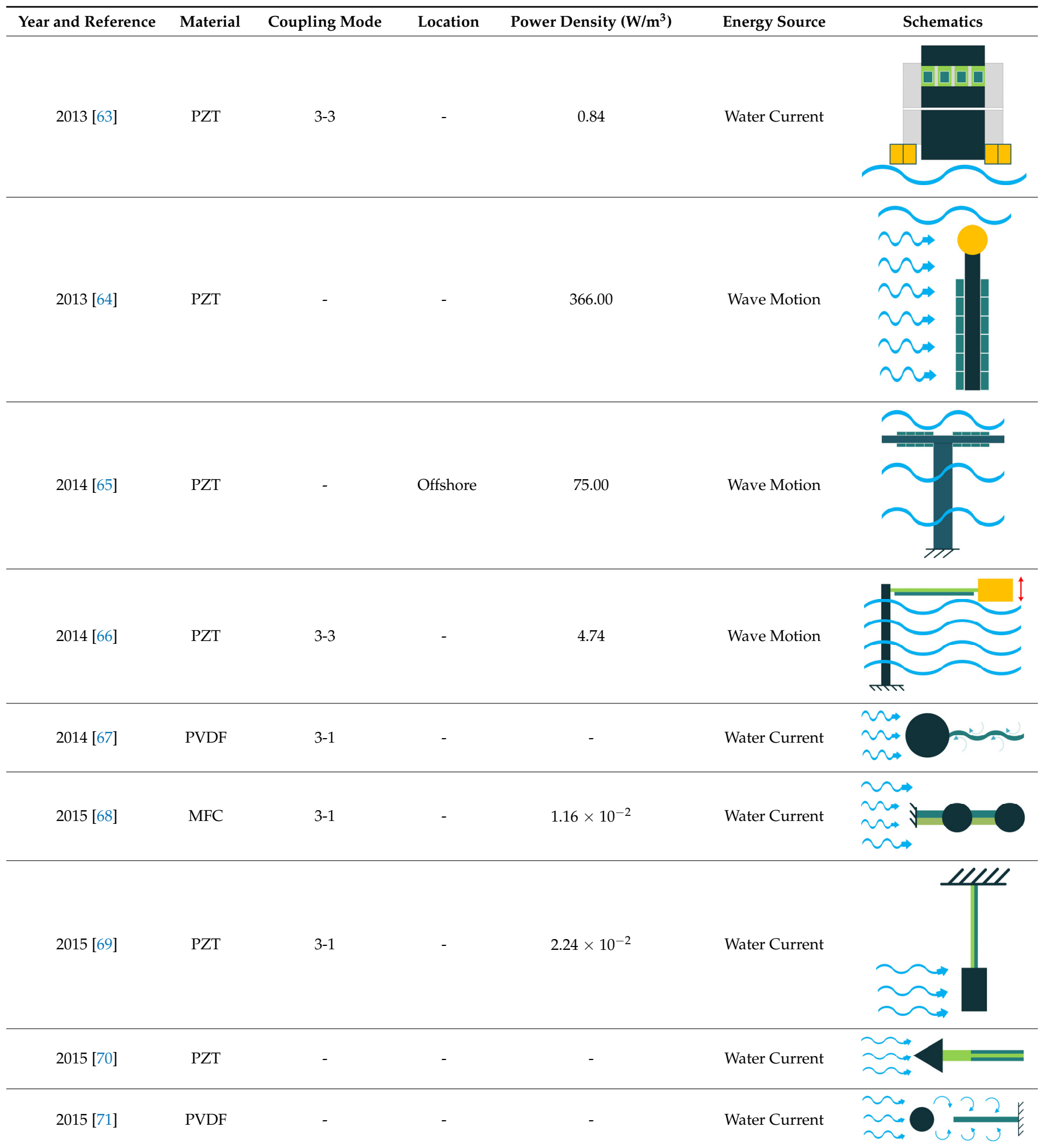


Table 2. Cont.

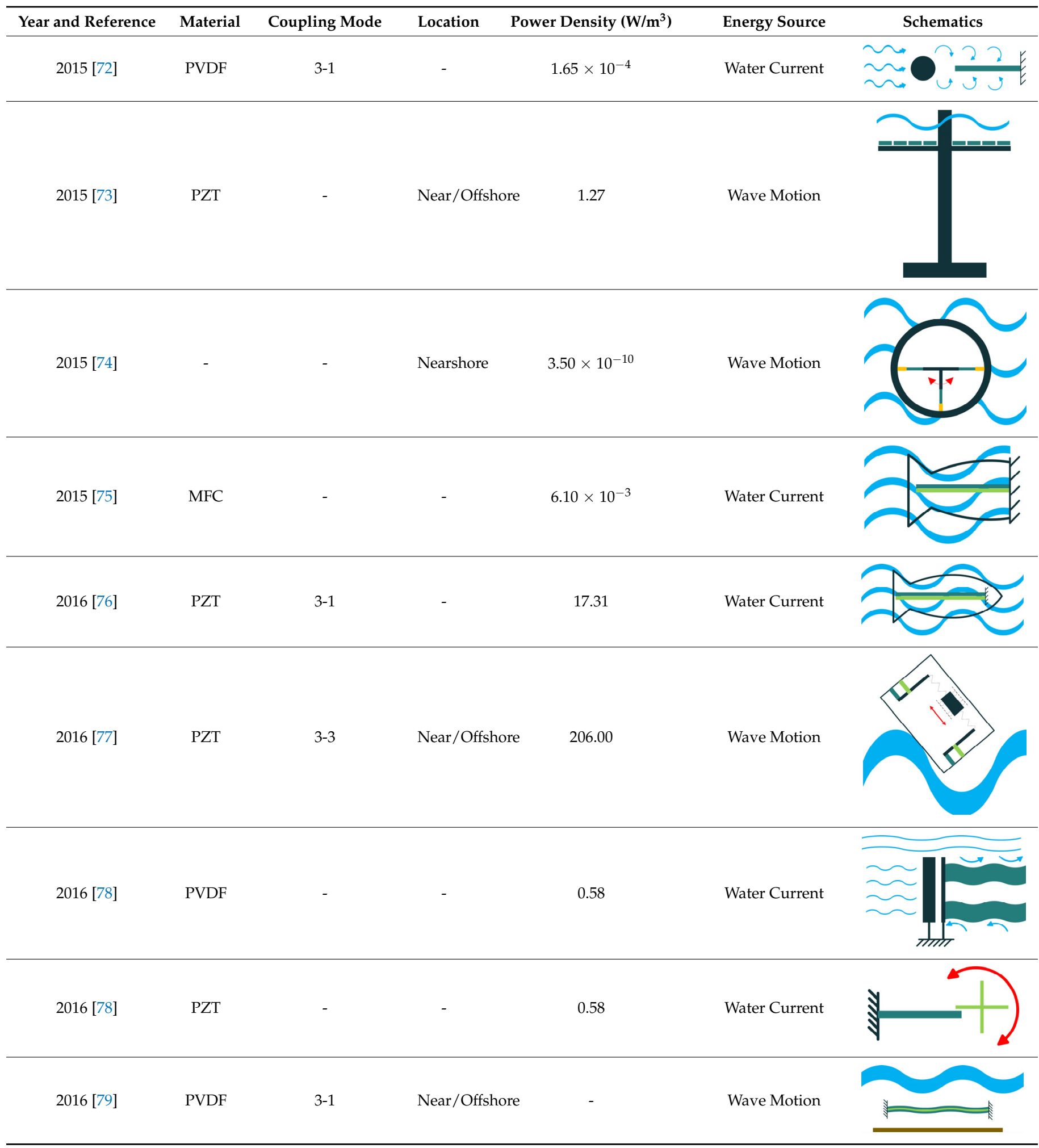


Table 2. Cont.

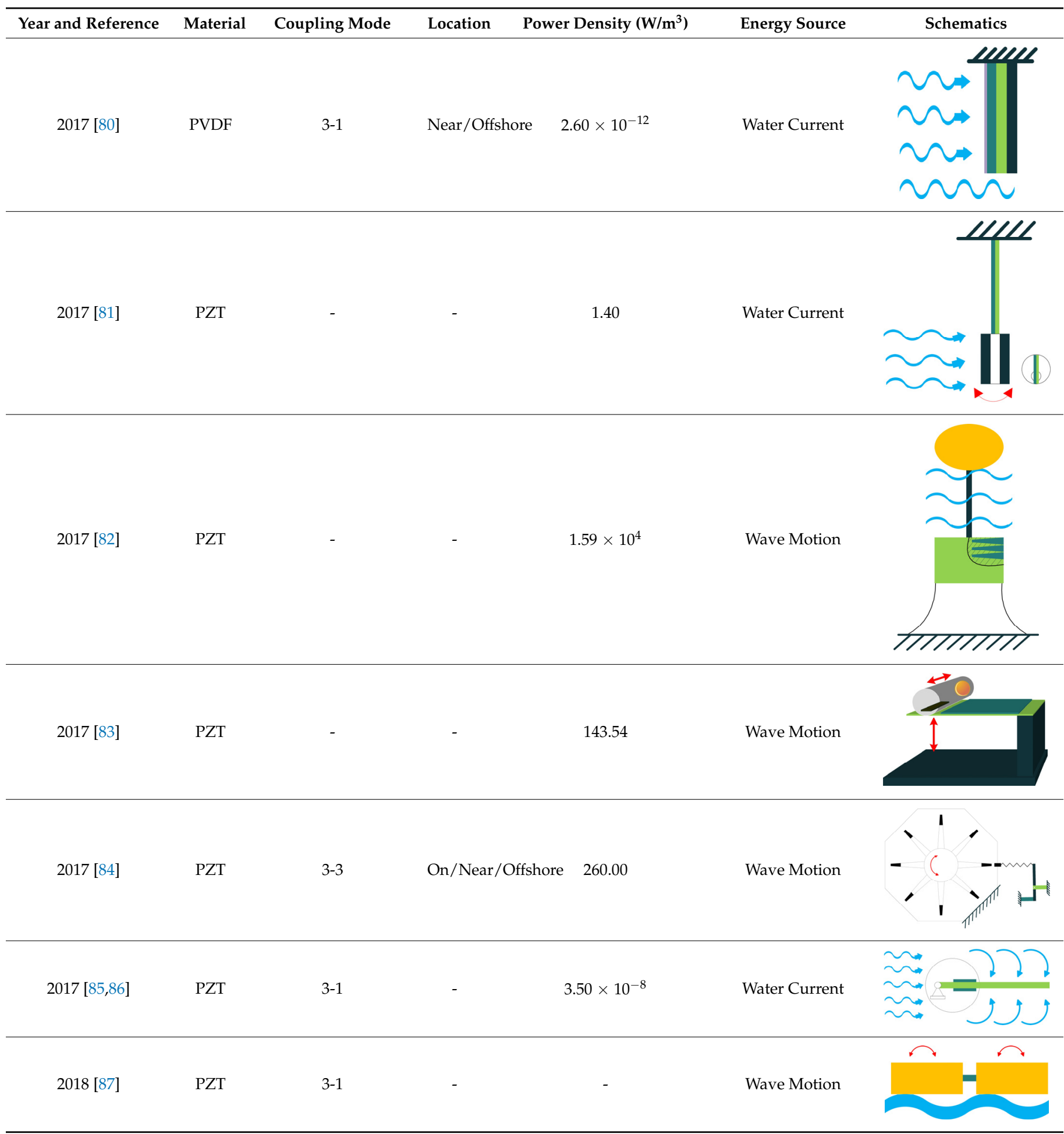


Table 2. Cont.

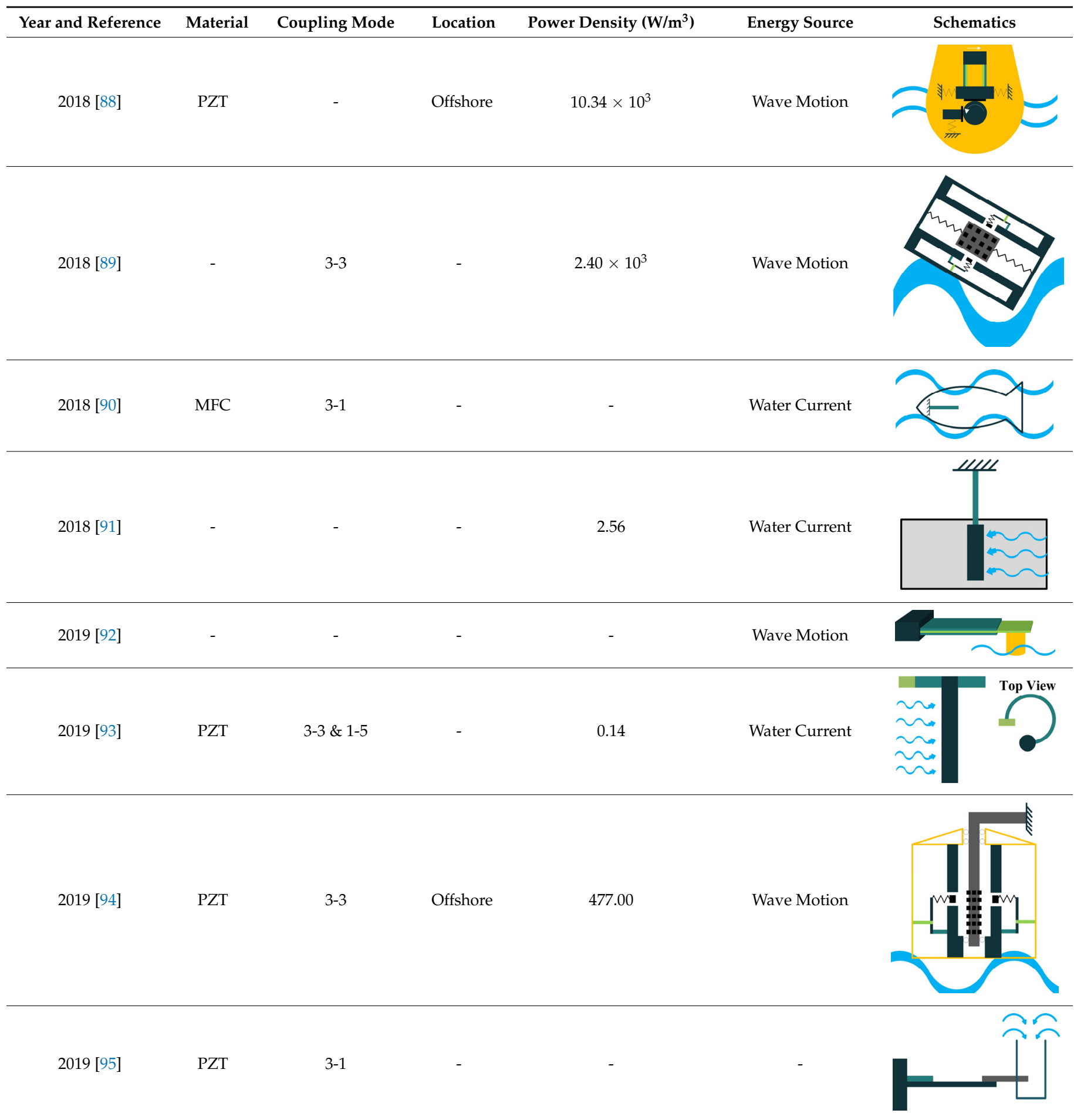


Table 2. Cont.

\begin{tabular}{|c|c|c|c|c|c|c|}
\hline Year and Reference & Material & Coupling Mode & Location & Power Density $\left(\mathrm{W} / \mathrm{m}^{3}\right)$ & Energy Source & Schematics \\
\hline $2019[96]$ & PZT & - & Nearshore & $1.06 \times 10^{4}$ & Wave Motion & \\
\hline $2019[24]$ & - & $3-1$ & Onshore & - & Wave Impact & \\
\hline 2019 [97] & PVDF & $3-1$ & Offshore & $2.00 \times 10^{-7}$ & Wave Motion & \\
\hline
\end{tabular}


Table 2. Cont.

\begin{tabular}{|c|c|c|c|c|c|c|}
\hline Year and Reference & Material & Coupling Mode & Location & Power Density $\left(\mathrm{W} / \mathrm{m}^{3}\right)$ & Energy Source & Schematics \\
\hline 2019 [101] & PZT & - & - & - & Water Current & \\
\hline 2019 [102] & PZT & - & Offshore & 140.00 & Wave Motion & \\
\hline 2020 [103] & PVDF & - & - & - & Water Current & \\
\hline 2020 [104] & PZT & $3-1$ & - & $7.34 \times 10^{-2}$ & Water Current & \\
\hline 2020 [105] & MFC & - & - & - & Water Current & \\
\hline 2020 [106] & PZT & - & - & - & Wave Motion & \\
\hline 2020 [107] & PVDF & - & - & - & Water Current & \\
\hline $2020[108]$ & PZT & - & - & $5.74 \times 10^{-8}$ & Water Current & \\
\hline 2021 [109] & - & - & - & 12.90 & Wave Motion & \\
\hline
\end{tabular}


Table 2. Cont.

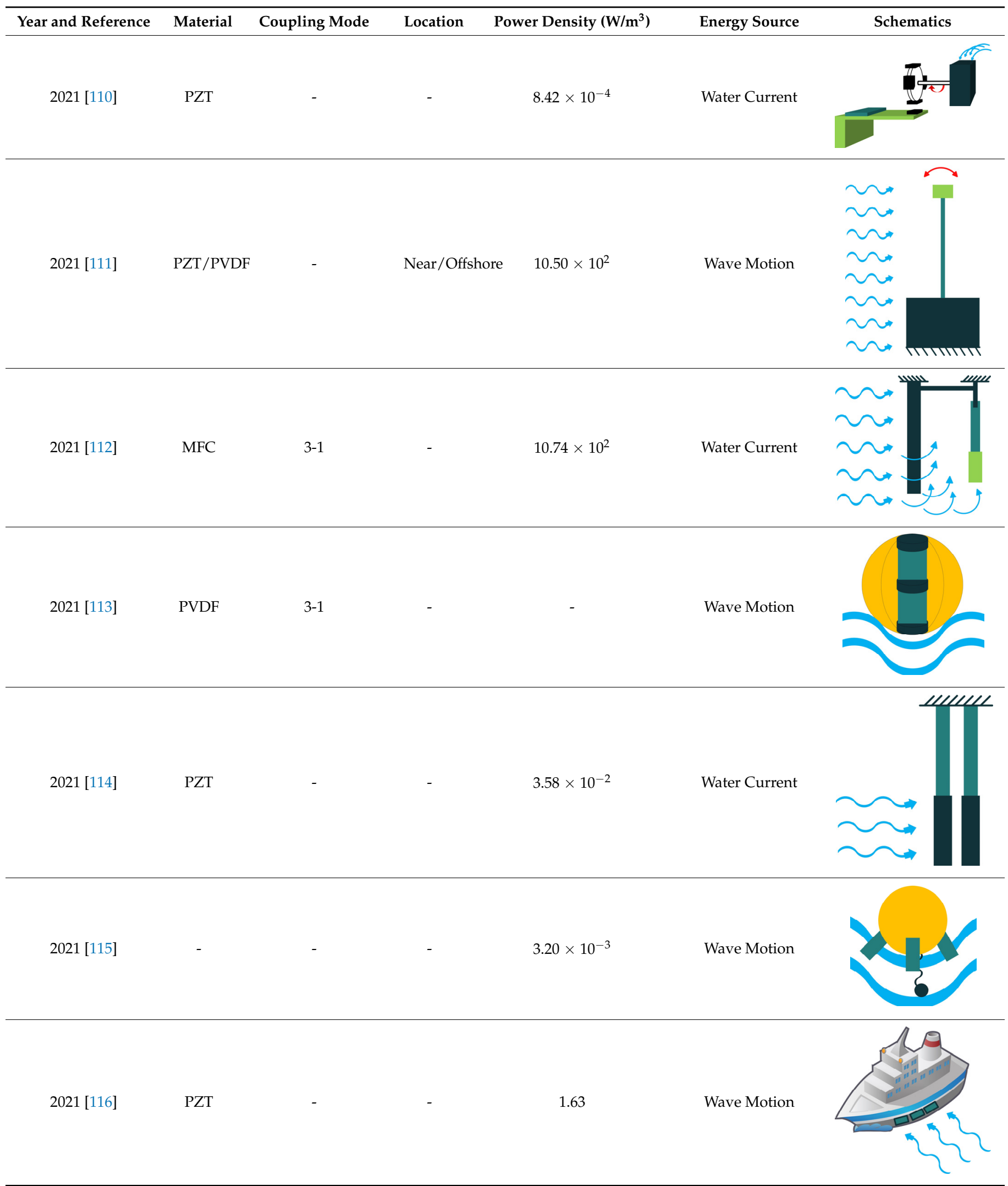


Table 2. Cont.

\begin{tabular}{|c|c|c|c|c|c|c|}
\hline Year and Reference & Material & Coupling Mode & Location & Power Density $\left(\mathrm{W} / \mathrm{m}^{3}\right)$ & Energy Source & Schematics \\
\hline 2021 [117] & - & - & - & - & Wave Motion & \\
\hline 2021 [118] & $\mathrm{PZT} / \mathrm{MFC}$ & - & - & $62.00 \times 10^{3}$ & Wave Motion & \\
\hline 2021 [119] & $\mathrm{PZT}$ & - & Offshore & - & Wave Motion & \\
\hline 2021 [120] & PZT & - & - & - & Wave Motion & \\
\hline 2021 [121] & - & - & Nearshore & - & Wave Motion & \\
\hline 2021 [122] & MFC & $3-3$ & - & $8.50 \times 10^{-3}$ & Wave Motion & \\
\hline
\end{tabular}

Table 3. Atlas of diaphragm-based piezoelectric energy harvesters.

\begin{tabular}{|c|c|c|c|c|c|c|}
\hline Year and Reference & Material & Coupling Mode & Location & Power Density $\left(\mathrm{W} / \mathrm{m}^{3}\right)$ & Energy Source & Schematics \\
\hline 2010 [123] & PVDF & $3-1$ & - & $1.90 \times 10^{-2}$ & Water Current & \\
\hline 2011 [124] & $\mathrm{PZT}$ & $1-5$ & - & $7.25 \times 10^{-5}$ & Water Current & \\
\hline 2013 [125] & PZT & - & Offshore & 0.34 & Water Current & \\
\hline
\end{tabular}


Table 3. Cont.

\begin{tabular}{|c|c|c|c|c|c|c|}
\hline Year and Reference & Material & Coupling Mode & Location & Power Density $\left(\mathrm{W} / \mathrm{m}^{3}\right)$ & Energy Source & Schematics \\
\hline 2013 [126] & $\mathrm{PZT}$ & - & Offshore & - & Wave Motion & \\
\hline 2013 [127] & $\mathrm{PZT}$ & - & Offshore & - & Wave Motion & \\
\hline 2018 [128] & PZT & $3-3$ & - & - & Water Current & \\
\hline 2019 [129] & PVDF & - & - & $5.68 \times 10^{-2}$ & Wave Motion & \\
\hline
\end{tabular}

Table 4. Atlas of stacked-based piezoelectric energy harvesters.

\begin{tabular}{|c|c|c|c|c|c|c|}
\hline Year and Reference & Material & Coupling Mode & Location & Power Density $\left(\mathrm{W} / \mathrm{m}^{3}\right)$ & Energy Source & Schematics \\
\hline 2013 [50] & PVDF & $3-3$ & - & - & Wave Impact & \\
\hline 2017 [130] & PZT & - & Offshore & 600.00 & Wave Impact & \\
\hline 2021 [131] & PZT & - & - & - & Wave Motion & \\
\hline
\end{tabular}


Table 5. Atlas of cymbal-based piezoelectric energy harvesters.

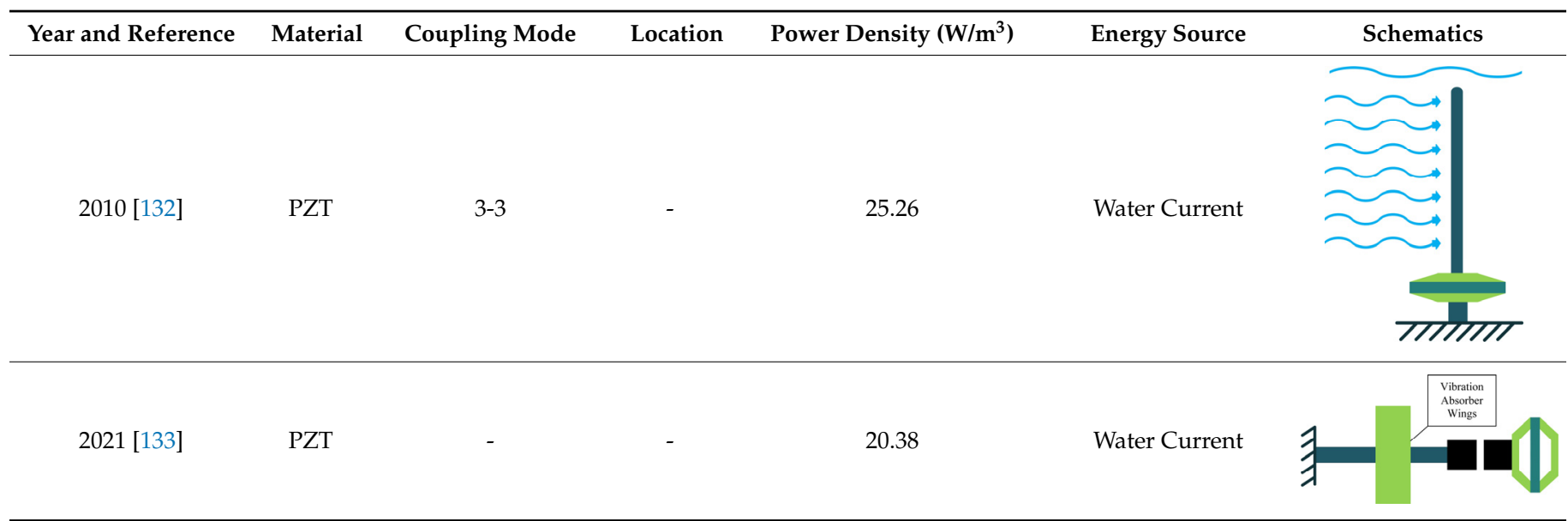

\section{Discussions and Research Needs}

There are huge amounts of energy in oceans in different forms, which can be converted to electricity using many different technologies. Wave motion, water current, and wave impact are the three most commonly used sources of energy in piezoelectric energy harvesters to extract low-power electricity from the oceans. As completely reviewed, many methods have been developed to convert ocean energy using piezoelectric materials for low power devices, such as sensors and IoT things. There are, however, challenges in the field of piezoelectric energy harvesters in ocean engineering, which should be addressed for future developments. In order to develop the field, several directions are proposed to fill the gaps and enhance the performance of future designs.

\subsection{Configurations}

As discussed in Section 2.4, four different configurations are utilized to harvest electrical energy from the ocean by piezoelectric materials: cantilever beam; diaphragm; stacked; and cymbal configurations. Table 6 shows the range of output power in each of the aforementioned configurations for energy harvesting from oceans. As it is clear from Table 6, the cantilever beam-based configuration covers a wide range of output power in the oceanic application.

Table 6. Output power range in different configurations in the oceanic application.

\begin{tabular}{cccccc}
\hline Type of Configuration & $\mathbf{n W}$ & $\boldsymbol{\mu W}$ & $\mathbf{m W}$ & $\mathbf{W}$ & $\mathbf{k W}$ \\
\hline Cantilever Beam & - & $\mathbf{0}$ & $\mathbf{0}$ & $\mathbf{\square}$ & $\mathbf{\square}$ \\
Diaphragm & $\mathbf{0}$ & $\mathbf{\square}$ & $\mathbf{0}$ & - & - \\
Stacked & - & $\mathbf{0}$ & $\mathbf{0}$ & - & - \\
Cymbal & - & $\mathbf{\square}$ & $\mathbf{0}$ & - \\
\hline
\end{tabular}

Ocean waves contain enormous energy inside but with a low frequency [134], which is the main challenge considering the high natural frequency of piezoelectric materials [11]. The cantilever beam configuration has a much lower resonance frequency compared to the other configurations. Moreover, by attaching a proof mass to the free end of the beam, its resonance frequency can be further lowered. Therefore, other than its simple structure and low cost, it can be easily employed for a higher range of output power, as well as various applications [34].

Introducing a medium device to translate low-frequency wave motion to a higher order of magnitude vibration is another solution for matching the resonance frequency of the oceanic waves with the energy harvester's $[56,126,127]$. This solution opens a wide range of opportunities for the other configurations to be widely employed in oceanic applications. 
Being unable to withstand high impact forces makes cantilever beam-based configurations susceptible to damage by the high forces of the ocean waves [34]. Therefore, developing novel medium structures to match the resonance frequency of the other configurations with that of ocean waves seems necessary and can be considered as a gap in the development of the other configurations for a higher range of power outputs in oceanic applications [11].

As the waves' energy density diminishes with depth and is concentrated near the surface of the ocean, it is of high importance to optimize the existing techniques and develop other novel strategies to excite piezoelectric materials by the low-frequency motion of the ocean waves to provide electricity for low-power devices at the surface of the ocean [11].

\subsection{Material}

According to Section 2.2, PZT, PVDF, and MFC are the main piezoelectric materials for harvesting electrical energy from the oceans. As shown in Figure 12, PZT is the most utilized material in ocean energy harvesting because of its remarkable properties (Table 7). In addition to excellent dielectric and piezoelectric properties and a higher $\mathrm{d}_{31}$ value, PZT also has a high Curie temperature, above which piezoelectric materials undergo a sharp change that leads to losing their piezoelectricity [135]. Over time, to make it applicable in diverse applications, its chemical compositions have been modified regularly, meaning that PZT maintains the largest family among piezoelectric materials with a wide range of material properties at a low cost [136]. Therefore, owning great properties at a low cost makes PZTs the first choice for energy harvesting applications. However, PZT is brittle and fragile by its nature; it shows an elongation of $0.1 \%$ at break. Therefore, PVDF, due to its flexibility, is utilized in applications that need to bear higher loadings. This material has a much lower Young's modulus compared to that of PZT (Table 7) and shows an elongation of $10 \%$ at break. On the other hand, PVDF's power density is much lower than that of PZT, which introduces issues related to the size of the harvester in applications where high output power is needed. MFC material seems to be a kind of trade-off between these two materials by having both higher flexibility and higher power density than PZT and PVDF, respectively [137]. It is highly recommended to consider MFCs in future designs for their great properties, such as a lower Young's modulus than PZT and a higher $\mathrm{d}_{31}$ constant than PVDF.

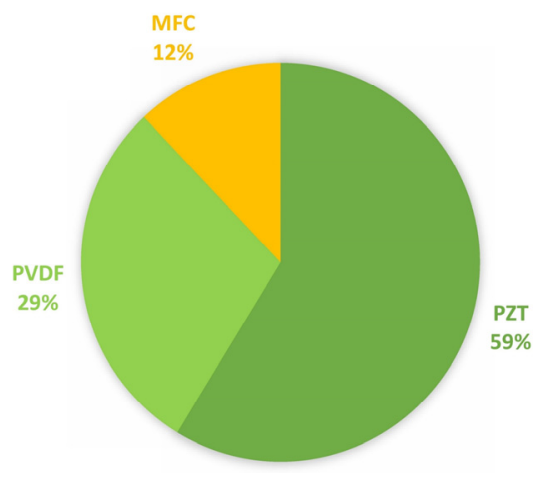

Figure 12. Frequency of different materials' usage in oceanic applications.

Table 7. Properties of piezoelectric materials used in oceanic energy harvesters.

\begin{tabular}{ccccc}
\hline Type of Material & $\begin{array}{c}\text { Young's Modulus } \\
\text { (GPa) }\end{array}$ & $\begin{array}{c}\mathbf{d}_{\mathbf{3 1}} \\
\left(\times \mathbf{1 0}^{-\mathbf{1 2}} \mathbf{~ m} / \mathbf{V}\right)\end{array}$ & $\mathbf{k}_{\mathbf{3 1}}$ & Dielectric Constant \\
\hline PZT & 62 & 320 & 0.44 & $\sim 3800$ \\
PVDF & $2-4$ & 23 & 0.12 & $\sim 12-13$ \\
MFC & 16 & 170 & - & - \\
\hline
\end{tabular}

It is also reported that the composites of PZT-PVDF show better performance in electrical and mechanical properties compared to MFCs [138]. This composite could be 
one of the most promising materials for future energy harvesters in oceanic applications. Therefore, it is highly suggested to consider PZT-PVDF composites in future designs of energy harvesters in oceanic applications.

\subsection{Coupling Modes}

As completely reviewed in Section 2.3, according to [28], four different coupling modes are utilized in piezoelectric-based energy harvesters in oceanic applications: 3-1, 3-3, 1-4, and 1-5 modes. However, the 1-4 coupling mode is not directly mentioned in the recent research papers, and thus the developed atlas only contains 3-1, 3-3, and 1-5 coupling modes. Figure 13 illustrates the frequency of usage for different coupling modes for piezoelectric energy harvesters in oceanic applications. As can be seen in Figure 13, the frequency of 3-1 coupling usage is higher than the other two coupling modes. However, according to [26], the 3-1 coupling mode has the lowest piezoelectric coefficient and, consequently, it should have the lowest output power among these three coupling modes. The reason behind their wider applications is that the majority of the piezoelectric energy harvesters in oceanic applications are designed based on cantilever beams, and the 3-1 coupling mode is the best choice for a cantilever beam-based harvester since in this mode, the polar axis is not directly subjected to the input stress and applying large strains by bending deformation of the harvester perpendicular to the polar axis is much easier [26,135]. According to the atlas and $[26,28]$, designs based on the 3-1 coupling mode are the simplest structures, such as a simple tape, a film, or a cantilever beam, which are bonded to a piezoelectric material for energy harvesting purposes. Although, in comparison to the 3-3 coupling mode, the 3-1 coupling mode produces a lower output voltage, it shows a larger output current [33].

Considering that the output power of the 3-1 coupling mode is 3 times and 3-6 times lower than that of the 3-3 and 1-5 coupling modes, respectively, it is of high significance to consider 3-3 and 1-5 coupling modes to improve the output power in future designs. Although employing a 1-5 coupling mode due to its shear configuration is challenging, it can lead to a higher power density in piezoelectric energy harvesters. Therefore, it is suggested to develop techniques to utilize 1-5 coupling modes in future designs for higher output powers.

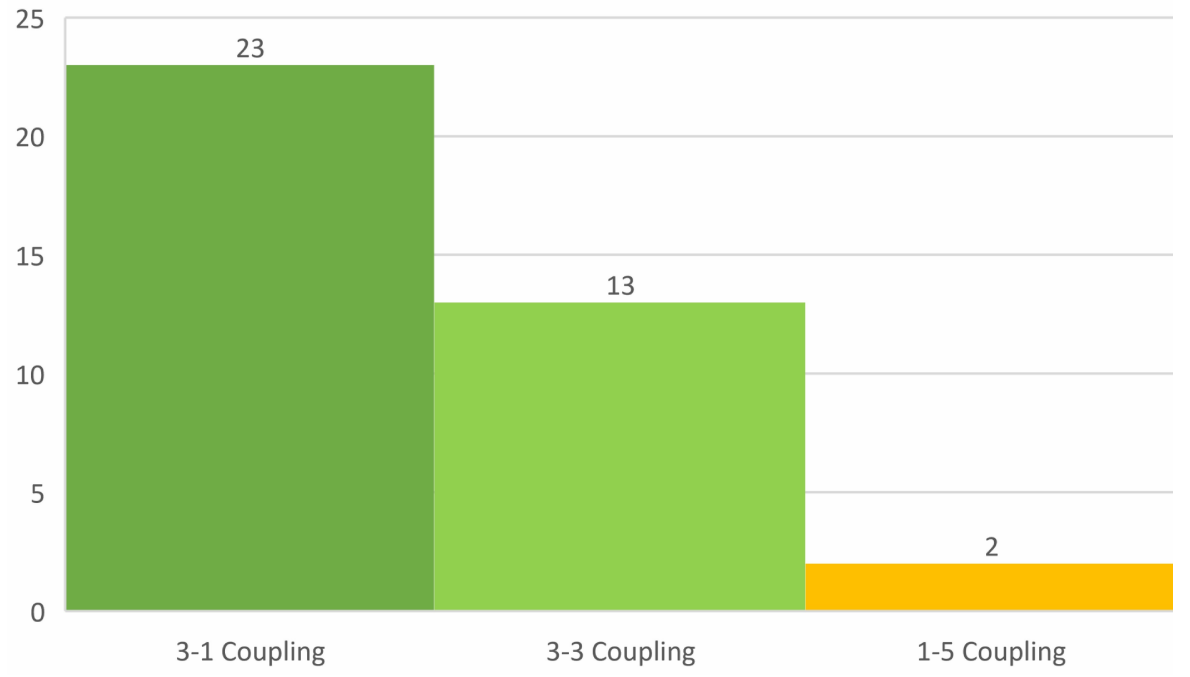

Figure 13. Frequency of different coupling modes' usage in oceanic applications.

\subsection{Energy Sources}

Section 2.6 discusses the different energy sources available in the oceans to convert energy from. Figure 14 summarizes the different designs based on the energy sources as well as their output power. Designs based on ocean wave motion show a higher output power compared to the other two energy sources. Energy harvesters based on ocean wave motion can be employed to power buoys and measurement devices, such as sensors. As 
discussed earlier, the main issue with ocean wave motion is their low frequency, which should be considered to be matched by that of the piezoelectric material [134]. On the other hand, energy harvesters based on water currents have an average power output applicable for underwater moving devices. Due to their low hydrodynamic efficiency, they can only utilize a small fraction of the water currents' energy. To address this issue, many of these devices can be aligned to build a big farm to capture higher fractions of water currents energy $[11,59,60]$. The directions of the alignment need to be tuned carefully to reach the maximum available output power. The other concern with water current-based energy harvesters is their continuous contact with the ocean's corrosive water, which should be considered in the design stage of these energy harvesters to select proper materials [11].

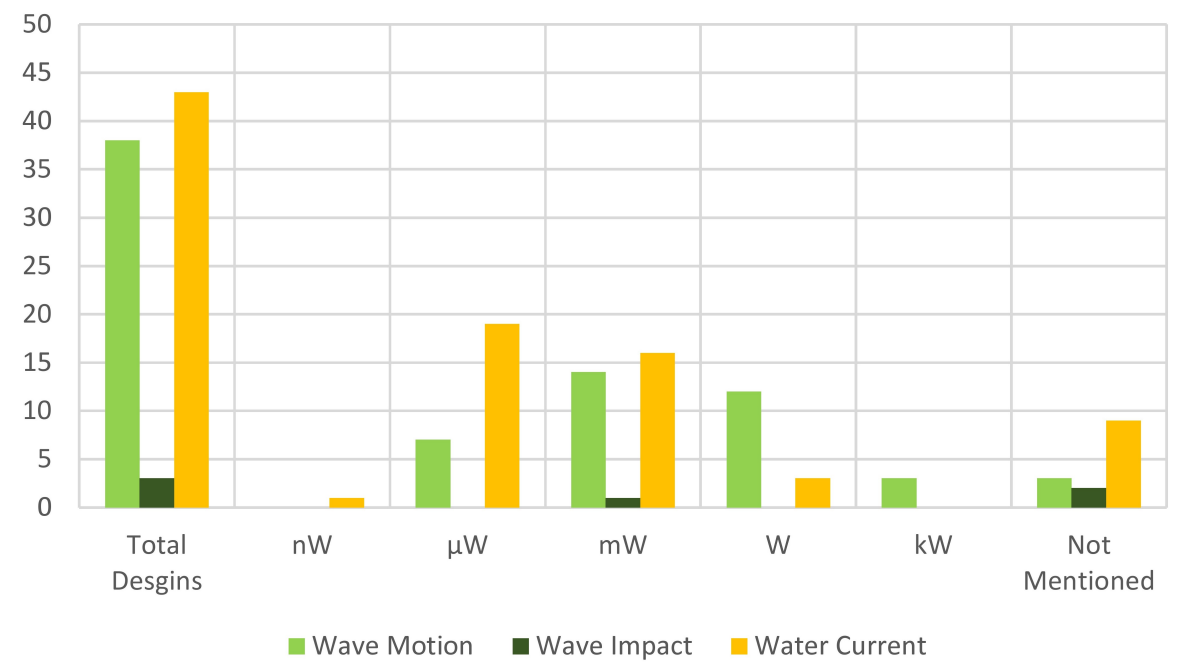

Figure 14. Comparison of the piezoelectric energy harvesters based on their energy sources and output power.

\subsection{Power}

Piezoelectric energy harvesters provide many different application scenarios by having flexibility in their structures, coupling modes, sizes, etc. Therefore, the amount of generated energy is different from one harvester to the next. An identical and standardized criterion is needed to compare oceanic piezoelectric energy harvesters. Here, maximum power per volume $\left(\mathrm{W} / \mathrm{m}^{3}\right)$ is adopted to show the designed structures' electrical performance. Moreover, as the volume of a harvester represents its structure, size, and applicability in different locations, it is used here to provide a comprehensive outlook on the state-of-the-art. Power density, as well as the volume of the designed piezoelectric energy harvesters, is utilized in Figure 15 to illustrate the relationship between designs in the literature. However, it is of high importance to mention that there may be errors/inaccuracies in Figure 15 due to: (1) power density and the volume of the designed devices may be computed in another way by the authors; (2) the number of designs that provided enough information for the Figure is limited; and (3) only the designs that have tested a prototype are considered for this analysis.

Several conclusions can be drawn based on Figure 15: (1) Among the three widely used materials in oceanic piezoelectric energy harvesters, PZT is used in a wide range of volumes and power densities. Due to its remarkable characteristics, it also shows the highest power density among the three materials used in oceanic applications; (2) MFC reaches the same high-power density as PZT but in a larger volume; and (3) As the piezoelectric coefficient of the PVDF is much lower than that of PZT and MFC, the volume of PVDF-based energy harvesters is higher than the others. 


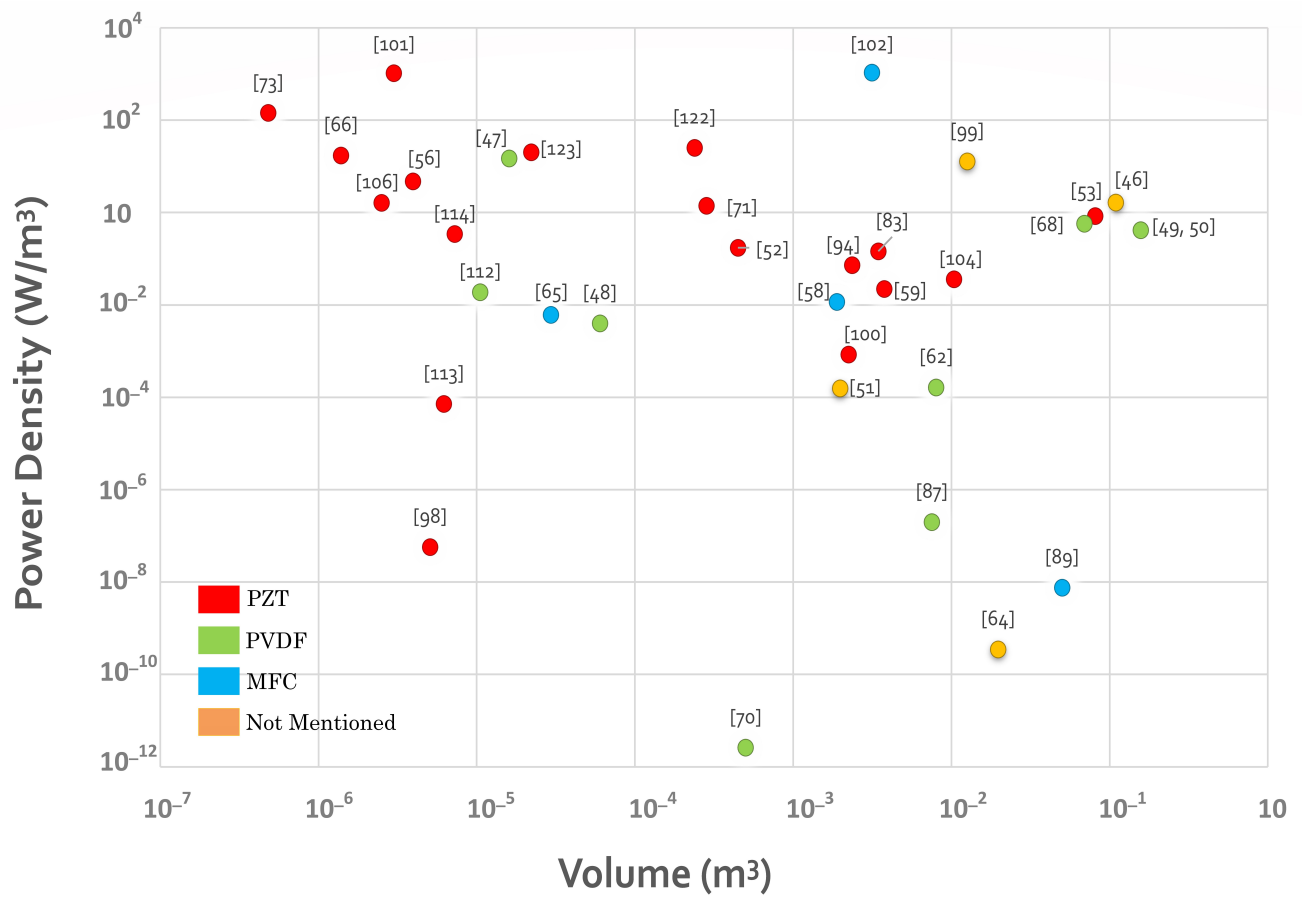

Figure 15. Power density per volume graph of the oceanic piezoelectric energy harvesters.

The statistics coming from Figure 13 can be used as a reference for material selection, harvester structure, power requirements, and the size of the energy harvester.

\section{Conclusions}

In this study, the main aspects of piezoelectric energy harvesters in oceanic applications are reviewed, and for more information, the reader is referred to the related references. Then, a comprehensive atlas of 85 piezoelectric energy harvesters, which are classified based on piezoelectric configurations (cantilever beam, diaphragm, stacked, and cymbal configurations), has been provided. The atlas includes information on material, piezoelectric coupling modes, location, power density, energy source, and finally, a unified schematic of the designs in the literature. Each design has been represented using its working principle, which is rather close to the original design. The collection includes designs that are fabricated or at least simulated. All the schematics are prepared in such a way that the working principle can be easily understood. In the end, the collection (atlas) has been analyzed in several aspects, such as configurations, materials, coupling modes, energy sources, and output power, to obtain research gaps and to help future designers in the field by making a recipe to select the right material, configuration, coupling mode, energy source, location, etc. The authors hope that this collection of designs will help researchers come up with their own energy harvesters for oceanic applications.

Author Contributions: Investigation, S.M.K.; supervision, G.H.; writing—original draft preparation, S.M.K.; writing - review and editing, G.H. All authors have read and agreed to the published version of the manuscript.

Funding: This project has been conducted as part of SELKIE Project. The SELKIE Project is funded by the European Regional Development Fund through the Ireland-Wales Cooperation programme (Grant Agreement No. Ireland-Wales 81874).

Institutional Review Board Statement: Not applicable.

Informed Consent Statement: Not applicable.

Conflicts of Interest: The authors declare no conflict of interest. 


\section{References}

1. Albaladejo, C.; Sánchez, P.; Iborra, A.; Soto, F.; López, J.A.; Torres, R. Wireless Sensor Networks for Oceanographic Monitoring: A Systematic Review. Sensors 2010, 10, 6948. [CrossRef] [PubMed]

2. Zhao, T.; Xu, M.; Xiao, X.; Ma, Y.; Li, Z.; Wang, Z.L. Recent progress in blue energy harvesting for powering distributed sensors in ocean. Nano Energy 2021, 88, 106199. [CrossRef]

3. Gong, Y.; Yang, Z.; Shan, X.; Sun, Y.; Xie, T.; Zi, Y. Capturing Flow Energy from Ocean and Wind. Energies 2019, $12,2184$. [CrossRef]

4. Liang, H.; Hao, G.; Olszewski, O.Z. A review on vibration-based piezoelectric energy harvesting from the aspect of compliant mechanisms. Sens. Actuators A Phys. 2021, 331, 112743. [CrossRef]

5. Mustapa, M.A.; Yaakob, O.B.; Ahmed, Y.M.; Rheem, C.-K.; Koh, K.K.; Adnan, F.A. Wave energy device and breakwater integration: A review. Renew. Sustain. Energy Rev. 2017, 77, 43-58. [CrossRef]

6. Bahaj, A.S. Generating electricity from the oceans. Renew. Sustain. Energy Rev. 2011, 15, 3399-3416. [CrossRef]

7. Jouanne, A.V.; Brekken, T. Wave energy research, development and demonstration at Oregon State University. In Proceedings of the 2011 IEEE Power and Energy Society General Meeting, Detroit, MI, USA, 24-28 July 2011; pp. 1-7.

8. De Sousa Prado, M.G.; Gardner, F.; Damen, M.; Polinder, H. Modelling and test results of the Archimedes wave swing. Proc. Inst. Mech. Eng. Part A J. Power Energy 2006, 220, 855-868. [CrossRef]

9. Torre-Enciso, Y.; Ortubia, I.; De Aguileta, L.L.; Marqués, J. Mutriku wave power plant: From the thinking out to the reality. In Proceedings of the 8th European Wave and Tidal Energy Conference, Uppsala, Sweden, 7-10 September 2009; pp. 319-329.

10. Kofoed, J.P.; Frigaard, P.; Friis-Madsen, E.; Sørensen, H.C. Prototype testing of the wave energy converter wave dragon. Renew. Energy 2006, 31, 181-189. [CrossRef]

11. Jbaily, A.; Yeung, R.W. Piezoelectric devices for ocean energy: A brief survey. J. Ocean Eng. Mar. Energy 2015, 1, 101-118 [CrossRef]

12. Despesse, G.; Chaillout, J.J.; Jager, T.; Léger, J.-M.; Vassilev, A.; Basrour, S.; Charlot, B. High damping electrostatic system for vibration energy scavenging. In Proceedings of the 2005 Joint Conference on Smart Objects and Ambient Intelligence: Innovative Context-Aware Services: Usages and Technologies, Grenoble, France, 12-14 October 2005; pp. 283-286.

13. Mizuno, M.; Chetwynd, D.G. Investigation of a resonance microgenerator. J. Micromech. Microeng. 2003, 13, 209-216. [CrossRef]

14. Shen, F.; Li, Z.; Guo, H.; Yang, Z.; Wu, H.; Wang, M.; Luo, J.; Xie, S.; Peng, Y.; Pu, H. Recent Advances towards Ocean Energy Harvesting and Self-Powered Applications Based on Triboelectric Nanogenerators. Adv. Electron. Mater. 2021, 7, 2100277. [CrossRef]

15. Jahanbakht, M.; Xiang, W.; Hanzo, L.; Azghadi, M.R. Internet of Underwater Things and Big Marine Data Analytics-A Comprehensive Survey. IEEE Commun. Surv. Tutor. 2021, 23, 904-956. [CrossRef]

16. Priya, S. Advances in energy harvesting using low profile piezoelectric transducers. J. Electroceram. 2007, 19, 167-184. [CrossRef]

17. Moure, A.; Izquierdo Rodríguez, M.A.; Rueda, S.H.; Gonzalo, A.; Rubio-Marcos, F.; Cuadros, D.U.; Pérez-Lepe, A.; Fernández, J.F. Feasible integration in asphalt of piezoelectric cymbals for vibration energy harvesting. Energy Convers. Manag. 2016, 112, 246-253. [CrossRef]

18. Kim, K.-B.; Cho, J.Y.; Jabbar, H.; Ahn, J.H.; Hong, S.D.; Woo, S.B.; Sung, T.H. Optimized composite piezoelectric energy harvesting floor tile for smart home energy management. Energy Convers. Manag. 2018, 171, 31-37. [CrossRef]

19. Wang, Z.; Tan, L.; Pan, X.; Liu, G.; He, Y.; Jin, W.; Li, M.; Hu, Y.; Gu, H. Self-Powered Viscosity and Pressure Sensing in Microfluidic Systems Based on the Piezoelectric Energy Harvesting of Flowing Droplets. ACS Appl. Mater. Interfaces 2017, 9, 28586-28595. [CrossRef]

20. Zaszczynska, A.; Sajkiewicz, P.; Gradys, A. Piezoelectric Scaffolds as Smart Materials for Neural Tissue Engineering. Polymers 2020, 12, 161. [CrossRef]

21. Deng, W.; Yang, T.; Jin, L.; Yan, C.; Huang, H.; Chu, X.; Wang, Z.; Xiong, D.; Tian, G.; Gao, Y.; et al. Cowpea-structured PVDF/ZnO nanofibers based flexible self-powered piezoelectric bending motion sensor towards remote control of gestures. Nano Energy 2019, 55, 516-525. [CrossRef]

22. Zhang, H.; Zhang, X.S.; Cheng, X.; Liu, Y.; Han, M.; Xue, X.; Wang, S.; Yang, F.; Smitha, A.S.; Zhang, H.; et al. A flexible and implantable piezoelectric generator harvesting energy from the pulsation of ascending aorta: In vitro and in vivo studies. Nano Energy 2015, 12, 296-304. [CrossRef]

23. Orrego, S.; Shoele, K.; Ruas, A.; Doran, K.; Caggiano, B.; Mittal, R.; Kang, S.H. Harvesting ambient wind energy with an inverted piezoelectric flag. Appl. Energy 2017, 194, 212-222. [CrossRef]

24. Nabavi, S.F.; Farshidianfar, A.; Afsharfard, A.; Khodaparast, H.H. An ocean wave-based piezoelectric energy harvesting system using breaking wave force. Int. J. Mech. Sci. 2019, 151, 498-507. [CrossRef]

25. Zurkinden, A.S.; Campanile, F.C.; Martinelli, L. Wave Energy Converter through Piezoelectric Polymers. In Proceedings of the Proceedings of the COMSOL Users Conference 2007, Grenoble, France, 23-24 October 2007.

26. Viet, N.V.; Wu, N.; Wang, Q. A review on energy harvesting from ocean waves by piezoelectric technology. J. Model. Mech. Mater. 2017, 1, 20160161. [CrossRef]

27. Kim, H.-M. Electroactive polymers for ocean kinetic energy harvesting: Literature review and research needs. J. Ocean Eng. Mar. Energy 2018, 4, 343-365. [CrossRef] 
28. Kiran, M.R.; Farrok, O.; Abdullah-Al-Mamun, M.; Islam, M.R.; Xu, W. Progress in Piezoelectric Material Based Oceanic Wave Energy Conversion Technology. IEEE Access 2020, 8, 146428-146449. [CrossRef]

29. Hamlehdar, M.; Kasaeian, A.; Safaei, M.R. Energy harvesting from fluid flow using piezoelectrics: A critical review. Renew. Energy 2019, 143, 1826-1838. [CrossRef]

30. Curie, P.; Curie, J. Développement par compression de l'électricité polaire dans les cristaux hémièdres à faces inclinées. Bull. Minéralogie 1880, 3, 90-93. [CrossRef]

31. Sezer, N.; Koç, M. A comprehensive review on the state-of-the-art of piezoelectric energy harvesting. Nano Energy 2021, 80, 105567. [CrossRef]

32. Anton, S.R.; Sodano, H.A. A review of power harvesting using piezoelectric materials (2003-2006). Smart Mater. Struct. 2007, 16, R1-R21. [CrossRef]

33. Liu, H.; Zhong, J.; Lee, C.; Lee, S.-W.; Lin, L. A comprehensive review on piezoelectric energy harvesting technology: Materials, mechanisms, and applications. Appl. Phys. Rev. 2018, 5, 041306. [CrossRef]

34. Aabid, A.; Raheman, M.A.; Ibrahim, Y.E.; Anjum, A.; Hrairi, M.; Parveez, B.; Parveen, N.; Mohammed Zayan, J. A Systematic Review of Piezoelectric Materials and Energy Harvesters for Industrial Applications. Sensors 2021, 21, 4145. [CrossRef]

35. Covaci, C.; Gontean, A. Piezoelectric Energy Harvesting Solutions: A Review. Sensors 2020, 20, 3512. [CrossRef] [PubMed]

36. Mishra, S.; Unnikrishnan, L.; Nayak, S.K.; Mohanty, S. Advances in Piezoelectric Polymer Composites for Energy Harvesting Applications: A Systematic Review. Macromol. Mater. Eng. 2019, 304, 1800463. [CrossRef]

37. Guyomar, D.; Badel, A.; Lefeuvre, E.; Richard, C. Toward energy harvesting using active materials and conversion improvement by nonlinear processing. IEEE Trans. Ultrason. Ferroelectr. Freq. Control 2005, 52, 584-595. [CrossRef] [PubMed]

38. Shu, Y.C.; Lien, I.C. A comparison between the standard and SSHI interfaces used in piezoelectric power harvesting. In Active E Passive Smart Structures and Integrated Systems; International Society of Photo Optical: Bellingham, WA, USA, 2007; Volume 6525, p. 652509.

39. Rathod, V.T. A Review of Electric Impedance Matching Techniques for Piezoelectric Sensors, Actuators and Transducers. Electronics 2019, 8, 169. [CrossRef]

40. Liang, J.; Liao, W.H. Impedance matching for improving piezoelectric energy harvesting systems. In Active and Passive Smart Structures and Integrated Systems 2010; SPIE: Bellingham, WA, USA, 2010; Volume 7643, pp. 181-192.

41. Wang, M.; Xia, Y.; Pu, H.; Sun, Y.; Ding, J.; Luo, J.; Xie, S.; Peng, Y.; Zhang, Q.; Li, Z. Piezoelectric Energy Harvesting from Suspension Structures with Piezoelectric Layers. Sensors 2020, 20, 3755. [CrossRef]

42. Jabbar, H.; Jung, H.J.; Chen, N.; Cho, D.H.; Sung, T.H. Piezoelectric energy harvester impedance matching using a piezoelectric transformer. Sens. Actuators A Phys. 2017, 264, 141-150. [CrossRef]

43. López, I.; Andreu, J.; Ceballos, S.; Martínez de Alegría, I.; Kortabarria, I. Review of wave energy technologies and the necessary power-equipment. Renew. Sustain. Energy Rev. 2013, 27, 413-434. [CrossRef]

44. Jiang, B.; Li, X.; Chen, S.; Xiong, Q.; Chen, B.-F.; Parker, R.G.; Zuo, L. Performance analysis and tank test validation of a hybrid ocean wave-current energy converter with a single power takeoff. Energy Convers. Manag. 2020, 224, 113268. [CrossRef]

45. Yeung, R. Fluid Dynamics of Finned Bodies-From VIV to FPSO. In Proceedings of the The Twelfth International Offshore and Polar Engineering Conference, Kitakyushu, Japan, 26 May 2002; Volume 12.

46. Akcabay, D.; Young, Y.L. Hydroelastic response and energy harvesting potential of flexible piezoelectric beams in viscous flow. Phys. Fluids 2012, 24, 054106. [CrossRef]

47. Toffoli, A.; Bitner-Gregersen, E.M. Types of Ocean Surface Waves, Wave Classification. In Encyclopedia of Maritime and Offshore Engineering; Carlton, J., Jukes, P., Choo, Y.S., Eds.; Wiley: Hoboken, NJ, USA, 2017; pp. 1-8. [CrossRef]

48. Guillou, N. Estimating wave energy flux from significant wave height and peak period. Renew. Energy 2020, $155,1383-1393$. [CrossRef]

49. Akimoto, H.; Tanaka, K.; Kim, Y.Y. Drag-type cross-flow water turbine for capturing energy from the orbital fluid motion in ocean wave. Renew. Energy 2015, 76, 196-203. [CrossRef]

50. Athanassoulis, G.A.; Mamis, K.I. Modeling and analysis of a cliff-mounted piezoelectric sea-wave energy absorption system. Coupled Syst. Mech. 2013, 2, 53-83. [CrossRef]

51. Farrok, O.; Ahmed, K.; Tahlil, A.D.; Farah, M.M.; Kiran, M.R.; Islam, M.R. Electrical Power Generation from the Oceanic Wave for Sustainable Advancement in Renewable Energy Technologies. Sustainability 2020, 12, 2178. [CrossRef]

52. Hausler, E.; Stein, L. Hydromechanical and physiological mechanical-to-electrical power converter with PVDF film. Ferroelectrics 1987, 75, 363-369. [CrossRef]

53. Burns, J.R. Ocean Wave Energy Conversion Using Piezoelectric Material Members. U.S. Patent 4,685,296, 11 August 1987.

54. Taylor, G.W.; Burns, J.R.; Kammann, S.A.; Powers, W.B.; Welsh, T.R. The Energy Harvesting Eel: A small subsurface ocean/river power generator. IEEE J. Ocean. Eng. 2001, 26, 539-547. [CrossRef]

55. Pobering, S.; Schwesinger, N. A Novel Hydropower Harvesting Device. In Proceedings of the 2004 International Conference on MEMS, NANO and Smart Systems (ICMENS'04), Banff, AB, Canada, 25-27 August 2004; pp. 480-485.

56. Murray, R.; Rastegar, J. Novel two-stage piezoelectric-based ocean wave energy harvesters for moored or unmoored buoys. In Active and Passive Smart Structures and Integrated Systems 2009; SPIE: Bellingham, WA, USA, 2009; Volume 7288, pp. 184-195. 
57. Mutsuda, H.; Kawakami, K.; Kurokawa, T.; Doi, Y.; Tanaka, Y. A Technology of Electrical Energy Generated From Ocean Power Using Flexible Piezoelectric Device. In Proceedings of the ASME 2010 29th International Conference on Ocean, Offshore and Arctic Engineering, Shanghai, China, 6-11 June 2010; pp. 313-321.

58. Mutsuda, H.; Kawakami, K.; Hirata, M.; Doi, Y.; Tanaka, Y. Study on Wave Power Generator Using Flexible Piezoelectric Device In Proceedings of the ASME 2011 30th International Conference on Ocean, Offshore and Arctic Engineering, Rotterdam, The Netherlands, 19-24 June 2011; pp. 267-273.

59. Mutsuda, H.; Watanabe, R.; Hirata, M.; Doi, Y.; Tanaka, Y. Elastic Floating Unit With Piezoelectric Device for Harvesting Ocean Wave Energy. In Proceedings of the ASME 2012 31st International Conference on Ocean, Offshore and Arctic Engineering, Rio de Janeiro, Brazil, 1-6 July 2012; pp. 233-240.

60. Mutsuda, H.; Watanabe, R.; Azuma, S.; Tanaka, Y.; Doi, Y. Ocean Power Generator Using Flexible Piezoelectric Device. In Proceedings of the ASME 2013 32nd International Conference on Ocean, Offshore and Arctic Engineering, Nantes, France, 9-14 June 2013.

61. Molino-Minero-Re, E.; Carbonell-Ventura, M.; Fisac-Fuentes, C.; Mànuel-Làzaro, A.; Toma, D.M. Piezoelectric energy harvesting from induced vortex in water flow. In Proceedings of the 2012 IEEE International Instrumentation and Measurement Technology Conference Proceedings, Graz, Austria, 13-16 May 2012; pp. 624-627.

62. Okada, N.; Fujimoto, H.; Yabe, S.; Murai, M. Experiments on floating wave-power generation using piezoelectric elements and pendulums in the water tank. In Proceedings of the the 2012 Oceans-Yeosu, Yeosu, Korea, 21-24 May 2012; pp. 1-8.

63. Kim, K.-B.; Kim, C.I.; Jeong, Y.H.; Cho, J.-H.; Paik, J.-H.; Nahm, S.; Lim, J.B.; Seong, T.-H. Energy Harvesting Characteristics from Water Flow by Piezoelectric Energy Harvester Device Using $\mathrm{Cr} / \mathrm{Nb}$ Doped Pb(Zr,Ti)O3Bimorph Cantilever. Jpn. J. Appl. Phys. 2013, 52, 10MB01. [CrossRef]

64. Xie, X.D.; Wang, Q.; Wu, N. Potential of a piezoelectric energy harvester from sea waves. J. Sound Vib. 2014, 333, 1421-1429. [CrossRef]

65. Xie, X.D.; Wang, Q.; Wu, N. Energy harvesting from transverse ocean waves by a piezoelectric plate. Int. J. Eng. Sci. 2014, 81, 41-48. [CrossRef]

66. Woo, M.S.; Baek, K.H.; Kim, J.H.; Kim, S.B.; Song, D.; Sung, T.H. Relationship between current and impedance in piezoelectric energy harvesting system for water waves. J. Electroceram. 2015, 34, 180-184. [CrossRef]

67. Gao, X.; Xu, Z.; Gu, J.; Pan, F.; Dong, X. A study of piezoelectric generator based on the flow around a blunt body. In Proceedings of the 2014 17th International Conference on Electrical Machines and Systems (ICEMS), Hangzhou, China, 22-25 October 2014; pp. 2877-2881.

68. Song, R.; Shan, X.; Lv, F.; Li, J.; Xie, T. A Novel Piezoelectric Energy Harvester Using the Macro Fiber Composite Cantilever with a Bicylinder in Water. Appl. Sci. 2015, 5, 1942. [CrossRef]

69. Song, R.; Shan, X.; Lv, F.; Xie, T. A study of vortex-induced energy harvesting from water using PZT piezoelectric cantilever with cylindrical extension. Ceram. Int. 2015, 41, S768-S773. [CrossRef]

70. Sarker, M.R.; Mohamed, A.; Mohamed, R. Cantilever beam vibration from fluid interactions with triangular shape blunt body for energy harvesting application. In Proceedings of the 2015 IEEE Student Conference on Research and Development (SCOReD), Kuala Lumpur, Malaysia, 13-14 December 2015; pp. 6-10.

71. Feifei, P.; Zhike, X.; Long, J.; Xiu, G. Designed simulation and experiment of a piezoelectric energy harvesting system based on flow around blunt bodies. In Proceedings of the 2015 18th International Conference on Electrical Machines and Systems (ICEMS), Pattaya, Thailand, 25-28 October 2015; pp. 2104-2107.

72. Shan, X.; Song, R.; Liu, B.; Xie, T. Novel energy harvesting: A macro fiber composite piezoelectric energy harvester in the water vortex. Ceram. Int. 2015, 41, S763-S767. [CrossRef]

73. $\mathrm{Wu}, \mathrm{N}$.; Wang, Q.; Xie, X. Ocean wave energy harvesting with a piezoelectric coupled buoy structure. Appl. Ocean Res. 2015, 50, 110-118. [CrossRef]

74. Toma, D.M.; del Rio, J.; Carbonell-Ventura, M.; Masalles, J.M. Underwater energy harvesting system based on plucked-driven piezoelectrics. In Proceedings of the OCEANS 2015-Genova, Genova, Italy, 18-21 May 2015; pp. 1-5.

75. Cha, Y.; Chae, W.; Kim, H.; Walcott, H.; Peterson, S.D.; Porfiri, M. Energy harvesting from a piezoelectric biomimetic fish tail. Renew. Energy 2016, 86, 449-458. [CrossRef]

76. Li, H.; Tian, C.; Lu, J.; Myjak, M.J.; Martinez, J.J.; Brown, R.S.; Deng, Z.D. An Energy Harvesting Underwater Acoustic Transmitter for Aquatic Animals. Sci. Rep. 2016, 6, 33804. [CrossRef] [PubMed]

77. Viet, N.V.; Xie, X.D.; Liew, K.M.; Banthia, N.; Wang, Q. Energy harvesting from ocean waves by a floating energy harvester. Energy 2016, 112, 1219-1226. [CrossRef]

78. Kamenar, E.; Zelenika, S.; Blažević, D.; Maćešić, S.; Gregov, G.; Marković, K.; Glažar, V. Harvesting of river flow energy for wireless sensor network technology. Microsyst. Technol. 2016, 22, 1557-1574. [CrossRef]

79. Renzi, E. Hydroelectromechanical modelling of a piezoelectric wave energy converter. Proc. R. Soc. A Math. Phys. Eng. Sci. 2016, 472, 20160715. [CrossRef]

80. Mutsuda, H.; Tanaka, Y.; Patel, R.; Doi, Y.; Moriyama, Y.; Umino, Y. A painting type of flexible piezoelectric device for ocean energy harvesting. Appl. Ocean Res. 2017, 68, 182-193. [CrossRef]

81. Shan, X.; Deng, J.; Song, R.; Xie, T. A Piezoelectric Energy Harvester with Bending-Torsion Vibration in Low-Speed Water. Appl. Sci. 2017, 7, 116. [CrossRef] 
82. Xie, X.D.; Wang, Q. A study on an ocean wave energy harvester made of a composite piezoelectric buoy structure. Compos. Struct. 2017, 178, 447-454. [CrossRef]

83. Hwang, W.S.; Ahn, J.H.; Jeong, S.Y.; Jung, H.J.; Hong, S.K.; Choi, J.Y.; Cho, J.Y.; Kim, J.H.; Sung, T.H. Design of piezoelectric ocean-wave energy harvester using sway movement. Sens. Actuators A Phys. 2017, 260, 191-197. [CrossRef]

84. Viet, N.V.; Wang, Q.; Carpinteri, A. Development of an ocean wave energy harvester with a built-in frequency conversion function. Int. J. Energy Res. 2018, 42, 684-695. [CrossRef]

85. An, X.; Song, B.; Tian, W.; Ma, C. Numerical simulation of Vortex Induced Piezoelectric Energy Converter (VIPEC) based on coupled fluid, structure and piezoelectric interaction. In Proceedings of the OCEANS 2017-Aberdeen, Aberdeen, UK, 19-22 June 2017; pp. 1-5.

86. An, X.; Song, B.; Tian, W.; Ma, C. Design and CFD Simulations of a Vortex-Induced Piezoelectric Energy Converter (VIPEC) for Underwater Environment. Energies 2018, 11, 330. [CrossRef]

87. Dessi, D.; Leonardi, G.; Passacantilli, F. Energy Harvesting From Waves Using Piezoelectric Floaters. In Proceedings of the ASME 2018 37th International Conference on Ocean, Offshore and Arctic Engineering, Madrid, Spain, 17-22 June 2018.

88. Nabavi, S.F.; Farshidianfar, A.; Afsharfard, A. Novel piezoelectric-based ocean wave energy harvesting from offshore buoys. Appl. Ocean Res. 2018, 76, 174-183. [CrossRef]

89. Nguyen, V.; Wang, Q. Ocean Wave Energy Pitching Harvester with a Frequency Tuning Capability. Energy 2018, 162, 603-617. [CrossRef]

90. Salazar, R.; Taylor, G.; Khalid, M.S.U.; Abdelkefi, A. Optimal design and energy harvesting performance of carangiform fish-like robotic system. Smart Mater. Struct. 2018, 27, 075045. [CrossRef]

91. Aramendia, I.; Fernandez-Gamiz, U.; Zulueta Guerrero, E.; Lopez-Guede, J.M.; Sancho, J. Power Control Optimization of an Underwater Piezoelectric Energy Harvester. Appl. Sci. 2018, 8, 389. [CrossRef]

92. Ming, L.; Hengxu, L.; Hailong, C.; Yuanchao, C.; Liquan, W. Performance Analysis for a Wave Energy Harvester of Piezoelectric Cantilever Beam. J. Coast. Res. 2019, 83, 976-984. [CrossRef]

93. Gong, Y.; Shan, X.; Yang, Z.; Xie, T. 270-degree arc-shaped piezoelectric energy converter in uniflow fluid environment. IOP Conf. Ser. Mater. Sci. Eng. 2019, 531, 012026. [CrossRef]

94. Viet, N.V.; Carpinteri, A.; Wang, Q. A Novel Heaving Ocean Wave Energy Harvester with a Frequency Tuning Capability. Arab. J. Sci. Eng. 2019, 44, 5711-5722. [CrossRef]

95. Bao, B.; Chen, W.; Wang, Q. A piezoelectric hydro-energy harvester featuring a special container structure. Energy 2019, 189, 116261. [CrossRef]

96. Zhang, J.; Xie, X.; Song, G.; Du, G.; Liu, D. A study on a near-shore cantilevered sea wave energy harvester with a variable cross section. Energy Sci. Eng. 2019, 7, 3174-3185. [CrossRef]

97. Mutsuda, H.; Tanaka, Y.; Doi, Y.; Moriyama, Y. Application of a flexible device coating with piezoelectric paint for harvesting wave energy. Ocean Eng. 2019, 172, 170-182. [CrossRef]

98. Gong, Y.; Shan, X.; Luo, X.; Pan, J.; Xie, T.; Yang, Z. Direction-adaptive energy harvesting with a guide wing under flow-induced oscillations. Energy 2019, 187, 115983. [CrossRef]

99. Sun, W.; Zhao, D.; Tan, T.; Yan, Z.; Guo, P.; Luo, X. Low velocity water flow energy harvesting using vortex induced vibration and galloping. Appl. Energy 2019, 251, 113392. [CrossRef]

100. Shan, X.; Li, H.; Yang, Y.; Feng, J.; Wang, Y.; Xie, T. Enhancing the performance of an underwater piezoelectric energy harvester based on flow-induced vibration. Energy 2019, 172, 134-140. [CrossRef]

101. Noh, H.-J.; Lee, J.-S.; Kim, Y.-J. Micro-energy harvesting based on vortex-induced vibration of cross-flow hydroturbine with various cantilever beam configurations. IOP Conf. Ser. Earth Environ. Sci. 2019, 240, 022034. [CrossRef]

102. Liu, H.-X.; Liu, M.; Chai, Y.-C.; Shu, G.-Y.; Jing, F.-M.; Wang, L.-Q. Piezoelectric Energy Analysis on Diverse Buoy Coupling with Hydrodynamic Parameters. China Ocean Eng. 2019, 33, 279-287. [CrossRef]

103. Yayla, S.; Ayça, S.; Oruç, M. A case study on piezoelectric energy harvesting with using vortex generator plate modeling for fluids. Renew. Energy 2020, 157, 1243-1253. [CrossRef]

104. Cao, D.; Ding, X.; Guo, X.; Yao, M. Design, Simulation and Experiment for a Vortex-Induced Vibration Energy Harvester for Low-Velocity Water Flow. Int. J. Precis. Eng. Manuf.-Green Technol. 2021, 8, 1239-1252. [CrossRef]

105. Shan, X.; Tian, H.; Xie, T. Enhanced performance of piezoelectric energy harvester through three serial vibrators. J. Intell. Mater. Syst. Struct. 2020, 32, 1140-1151. [CrossRef]

106. Du, X.; Zhao, Y.; Liu, G.; Zhang, M.; Wang, Y.; Yu, H. Enhancement of the Piezoelectric Cantilever Beam Performance via Vortex-Induced Vibration to Harvest Ocean Wave Energy. Shock Vib. 2020, 2020, 8858529. [CrossRef]

107. Latif, U.; Ali, E.; Uddin, E.; Ali, Z.; Sajid, M.; Shah, S.R.; Younis, M.Y. Experimental investigation of energy harvesting eel in the wake of bluff body under ocean waves. Proc. Inst. Mech. Eng. Part M J. Eng. Marit. Environ. 2020, 235, 81-92. [CrossRef]

108. Kim, S.; Cho, J.Y.; Jeon, D.H.; Hwang, W.; Song, Y.; Jeong, S.Y.; Jeong, S.W.; Yoo, H.H.; Sung, T.H. Propeller-based Underwater Piezoelectric Energy Harvesting System for an Autonomous IoT Sensor System. J. Korean Phys. Soc. 2020, 76, 251-256. [CrossRef]

109. Qi, L.; Li, H.; Wu, X.; Zhang, Z.; Duan, W.; Yi, M. A hybrid piezoelectric-electromagnetic wave energy harvester based on capsule structure for self-powered applications in sea-crossing bridges. Renew. Energy 2021, 178, 1223-1235. [CrossRef]

110. Bao, B.; Wang, Q. Bladeless rotational piezoelectric energy harvester for hydroelectric applications of ultra-low and wide-range flow rates. Energy Convers. Manag. 2021, 227, 113619. [CrossRef] 
111. Kazemi, S.; Nili-Ahmadabadi, M.; Tavakoli, M.R.; Tikani, R. Energy harvesting from longitudinal and transverse motions of sea waves particles using a new waterproof piezoelectric waves energy harvester. Renew. Energy 2021, 179, 528-536. [CrossRef]

112. Zhao, D.; Zhou, J.; Tan, T.; Yan, Z.; Sun, W.; Yin, J.; Zhang, W. Hydrokinetic piezoelectric energy harvesting by wake induced vibration. Energy 2021, 220, 119722. [CrossRef]

113. Jiao, P.; Yang, Y.; Egbe, K.I.; He, Z.; Lin, Y. Mechanical Metamaterials Gyro-Structure Piezoelectric Nanogenerators for Energy Harvesting under Quasi-Static Excitations in Ocean Engineering. ACS Omega 2021, 6, 15348-15360. [CrossRef]

114. Song, R.; Hou, C.; Yang, C.; Yang, X.; Guo, Q.; Shan, X. Modeling, Validation, and Performance of Two Tandem Cylinder Piezoelectric Energy Harvesters in Water Flow. Micromachines 2021, 12, 872. [CrossRef] [PubMed]

115. Mariello, M.; Fachechi, L.; Guido, F.; De Vittorio, M. Multifunctional sub-100 $\mu \mathrm{m}$ thickness flexible piezo/triboelectric hybrid water energy harvester based on biocompatible AlN and soft parylene C-PDMS-Ecoflex ${ }^{\mathrm{TM}}$. Nano Energy 2021, 83, 105811. [CrossRef]

116. Ucar, H. Patch-based piezoelectric energy harvesting on a marine boat exposed to wave-induced loads. Ocean Eng. 2021, 236, 109568. [CrossRef]

117. Zheng, S.; Meylan, M.; Zhang, X.; Iglesias, G.; Greaves, D. Performance of a plate-wave energy converter integrated in a floating breakwater. IET Renew. Power Gener. 2021, 15, 3206-3219. [CrossRef]

118. Salazar, R.; Quintana, R.; Abdelkefi, A. Role of Electromechanical Coupling, Locomotion Type and Damping on the Effectiveness of Fish-Like Robot Energy Harvesters. Energies 2021, 14, 693. [CrossRef]

119. Yulianti, S.; Kevin, P.; Prakoso, A. The Use of Piezoelectric as Energy Harvester in Breakwater. IOP Conf. Ser. Earth Environ. Sci. 2021, 750, 012016. [CrossRef]

120. Du, X.; Zhang, M.; Kang, H.; Chang, H.; Yu, H. Theoretical study on a novel piezoelectric ocean wave energy harvester driven by oscillating water column. Energy Sources Part A Recovery Util. Environ. Eff. 2021, 1-21. [CrossRef]

121. Alizzio, D.; Bonfanti, M.; Donato, N.; Faraci, C.; Grasso, G.M.; Lo Savio, F.; Montanini, R.; Quattrocchi, A. Design and Performance Evaluation of a "Fixed-Point" Spar Buoy Equipped with a Piezoelectric Energy Harvesting Unit for Floating Near-Shore Applications. Sensors 2021, 21, 1912. [CrossRef]

122. Tan, D.; Wang, Y.-C.; Kohtanen, E.; Erturk, A. Trout-like multifunctional piezoelectric robotic fish and energy harvester. Bioinspir Biomim. 2021, 16, 046024. [CrossRef]

123. Wang, D.A.; Ko, H.H. Piezoelectric energy harvesting from flow-induced vibration. J. Micromech. Microeng. Struct. Devices Syst. 2010, 20, 025019. [CrossRef]

124. Wang, D.-A.; Liu, N.-Z. A shear mode piezoelectric energy harvester based on a pressurized water flow. Sens. Actuators A Phys. 2011, 167, 449-458. [CrossRef]

125. Toma, D.M.; Ventura, M.C.; Bresco, D.P.; Lázaro, A.M.; Masalles, J.M. An impacting energy harvester through piezoelectric device for oscillating water flow. In Proceedings of the MARTECH 2013: 5th International Workshop on Marine Technology, Vilanova i la Geltrú, Spain, 19-20 November 2013.

126. Viñolo, C.; Toma, D.M.; Manuel, A.; del Río, J. Sea motion electrical energy generator for low-power applications. In Proceedings of the 2013 MTS/IEEE OCEANS-Bergen, Bergen, Norway, 10-14 June 2013; pp. 1-7.

127. Viñolo, C.; Toma, D.; Mànuel, A.; del Rio, J. An ocean kinetic energy converter for low-power applications using piezoelectric disk elements. Eur. Phys. J. Spec. Top. 2013, 222, 1685-1698. [CrossRef]

128. Abrol, S.; Chhabra, D.; Chhabra, D. Experimental Investigations of Piezoelectric Energy Harvesting with Turbulent Flow. Int. J. Mech. Prod. Eng. Res. Dev. 2018, 8, 703-710. [CrossRef]

129. Huang, W.; Huang, Y. A Study on Piezoelectric Buoy Energy Harvester Based on Orthogonal Experimental Design. In Proceedings of the 2019 IEEE International Conference on Power, Intelligent Computing and Systems (ICPICS), Shenyang, China, 12-14 July 2019; pp. 611-614.

130. Zhang, B.; Ducharne, B.; Gupta, B.; Sebald, G.; Guyomar, D.; Gao, J. Experimental sea wave energy extractor based on piezoelectric Ericsson cycles. J. Intell. Mater. Syst. Struct. 2017, 29, 1102-1112. [CrossRef]

131. Chen, S.-E.; Yang, R.-Y.; Wu, G.-K.; Wu, C.-C. A Piezoelectric Wave-Energy Converter Equipped with a Geared-Linkage-Based Frequency Up-Conversion Mechanism. Sensors 2021, 21, 204. [CrossRef]

132. Bezanson, L.; Thornton, J.; Konchuba, N.; Priya, S. Utilizing deep ocean currents to power extended duration sensors. In Proceedings of the OCEANS 2010 MTS/IEEE SEATTLE, Seattle, WA, USA, 20-23 September 2010; pp. 1-8.

133. Zou, H.-X.; Li, M.; Zhao, L.-C.; Gao, Q.-H.; Wei, K.-X.; Zuo, L.; Qian, F.; Zhang, W.-M. A magnetically coupled bistable piezoelectric harvester for underwater energy harvesting. Energy 2021, 217, 119429. [CrossRef]

134. Freris, L.; Infield, D. Renewable Energy in Power Systems; Wiley: Hoboken, NJ, USA, 2008.

135. Li, H.; Tian, C.; Deng, Z.D. Energy harvesting from low frequency applications using piezoelectric materials. Appl. Phys. Rev. 2014, 1, 041301. [CrossRef]

136. Shrout, T.R.; Zhang, S.J. Lead-free piezoelectric ceramics: Alternatives for PZT? J. Electroceram. 2007, 19, 113-126. [CrossRef]

137. Shen, D.; Choe, S.-Y.; Kim, D.-J. Comparison of Piezoelectric Materials for Vibration Energy Conversion Devices. MRS Online Proc. Libr. 2011, 966, 734. [CrossRef]

138. Pradhan, S.K.; Kumar, A.; Kour, P.; Pandey, R.; Kumar, P.; Kar, M.; Sinha, A.N. Piezoelectric and mechanical properties of PVDF-PZT composite. Ferroelectrics 2020, 558, 59-66. [CrossRef] 